\title{
The theory of feature systems: One feature versus two for Kayardild tense-aspect-mood
}

\author{
Erich R. Round ${ }^{1,2}$ • Greville G. Corbett ${ }^{2}$
}

Received: 21 October 2015 / Accepted: 5 May 2016 / Published online: 26 May 2016

(C) The Author(s) 2016. This article is published with open access at Springerlink.com

\begin{abstract}
Features are central to all major theories of syntax and morphology. Yet it can be a non-trivial task to determine the inventory of features and their values for a given language, and in particular to determine whether to postulate one feature or two in the same semantico-syntactic domain. We illustrate this from tense-aspectmood (TAM) in Kayardild, and adduce principles for deciding in general between one-feature and two-feature analyses, thereby contributing to the theory of feature systems and their typology.

Kayardild shows striking inflectional complexities, investigated in two major studies (Evans 1995a; Round 2013), and it proves particularly revealing for our topic. Both Evans and Round claimed that clauses in Kayardild have not one but two concurrent TAM features. While it is perfectly possible for a language to have two features of the same type, it is unusual. Accordingly, we establish general arguments which would justify postulating two features rather than one; we then apply these specifically to Kayardild TAM. Our finding is at variance with both Evans and Round; on all counts, the evidence which would motivate an analysis in terms of one TAM feature or two is either approximately balanced, or clearly favours an analysis with just one.
\end{abstract}

Thus even when faced with highly complex language facts, we can apply a principled approach to the question of whether we are dealing with one feature or two, and this is encouraging for the many of us seeking a rigorous science of typology. We also find that Kayardild, which in many ways is excitingly exotic, is in this one corner of its grammar quite ordinary.

\section{E.R. Round}

e.round@uq.edu.au;m08084@surrey.ac.uk

1 School of Languages and Cultures, University of Queensland, QLD 4072, Brisbane, Australia

2 Surrey Morphology Group, School of English and Languages, Faculty of Arts and Social Sciences, University of Surrey, Guildford, Surrey, GU2 7XH, UK 
Keywords Features · Typology · Morphosyntax · Inflection · Kayardild · Tense-aspect-mood

\section{Abbreviations}

ABL ablative

ABLC compass ablative

ABS absolutive

ACC accusative

ACT actual

ALL allative

ALLC compass allative

ANTE antecedent

AOBL associating oblique

APPR apprehensive

c complementized full clause

CASEN nominal case

CASEP pronominal case

CAUS causative

CNTRFCT counterfactual

COLL collative

COMP complementization

CONS consequential

CONT continuous

DAT dative

DES desiderative

DIR directed

DP determiner phrase

e embedded VP

EMO emotive

ERG ergative

FUNC functional

FUT future

HORT hortative

IMM immediate

IMP imperative

INCH inchoative

INCIP incipient

INS instantiated

J thematic element

LOC locative

LLOC long locative

$\mu \quad$ morphomic

MABL modal ablative

MALL modal allative

MOBL modal oblique

MLOC modal locative 


$\begin{array}{ll}\text { MPROP } & \text { modal proprietive } \\ \text { NEG } & \text { negative } \\ \text { NEGAT } & \text { negatory } \\ \text { NMLZ } & \text { nominalization } \\ \text { NOM } & \text { nominative } \\ \text { NONVER } & \text { nonveridical } \\ \text { OBL } & \text { oblique } \\ \text { PL } & \text { plural } \\ \text { POSS } & \text { possessive } \\ \text { POT } & \text { potential } \\ \text { PREC } & \text { precondition } \\ \text { PRES } & \text { present } \\ \text { PRIOR } & \text { prior } \\ \text { PRIV } & \text { privative } \\ \text { PROG } & \text { progressive } \\ \text { PROP } & \text { proprietive } \\ \text { PST } & \text { past } \\ \text { RDP } & \text { reduplication } \\ \text { RES } & \text { resultative } \\ \text { SEJ } & \text { sejunct } \\ \text { SG } & \text { singular } \\ \text { TAM } & \text { tense-aspect-mood } \\ \text { TAMA } & \text { athematic tense-aspect-mood } \\ \text { TAMT } & \text { thematic tense-aspect-mood } \\ \text { TAMV } & \text { verbal tense-aspect-mood } \\ \text { TH } & \text { thematic element } \\ \text { u } & \text { uncomplementized full clauses } \\ \text { VP } & \text { verb phrase } \\ \text { ZERO } & \text { zero } \\ & \end{array}$

\section{Introduction}

We discuss a fascinating issue in Kayardild. Anyone who has read Evans' grammar (1995a) is likely to have come away thinking that this is an amazing language. And Round (2013) shows that Kayardild is both more exotic and in other ways more "normal" than Evans suggests. Here we focus on one key issue in the analysis of Kayardild, namely the feature(s) of tense, aspect and mood (TAM). Both Evans and Round provide analyses in which Kayardild has two, concurrent features for TAM. ${ }^{1}$ Now this issue is itself of quite general interest. We normally expect to find that a language has, say, a case feature, which takes some range of values. Or it has no case feature, but hardly two case features, each with its own distinct set of values, operating concurrently within the clause. And while we do occasionally meet analyses which include concurrent features, this whole issue is rarely discussed (though

\footnotetext{
${ }^{1}$ This is therefore different to the issue discussed by Frajzyngier (2004), where languages appear to have two TAM systems in complementary distribution, such that a given clause makes use of only one of them.
} 
Goddard 1982 on case is an interesting exception). We will therefore revisit the issue of Kayardild's TAM feature(s). Our first aim is to elucidate the arguments which, more generally, are appropriate to support arguments in favour of one feature or two features. We then find that investigating the appropriate feature structures in this way leads us to question the previous analyses, to investigate the data further, and eventually to propose a more satisfying analysis. In short, we discuss a key theoretical issue, and we reanalyse a challenging system in a more elegant way.

\subsection{Kayardild}

Kayardild is a language of the non-Pama-Nyungan, Tangkic family of northern Australia; traditionally it was spoken primarily on Bentinck Island in the south of the Gulf of Carpentaria. Typologically, it can be characterized as an agglutinative, purely suffixing, dependent-marking language with nominative-accusative argument alignment. It has a fixed word order in DPs, but otherwise word order is free, to the extent that any order appears to be possible under appropriate contextual conditions. DPs and certain verbs of movement and transfer are freely elided if the meaning is recoverable from context. The language is treated in a comprehensive grammar (Evans 1995a), and in a formal analysis of morphology and syntax (Round 2013); see also Arkadiev (in press) for a careful comparison of these two works. Kayardild is of interest to us here because two substantial analyses have both characterized the majority if not all of Kayardild's clause types as involving two separate yet concurrent tenseaspect-mood (TAM) features: VERBAL TAM and MODAL CASE (Evans 1995a), or THEMATIC TAM and ATHEMATIC TAM (Round 2009, 2013). Consequently, the TAM system of Kayardild is 'exotic' in the sense mentioned above, and for that reason is of wide theoretical interest.

TAM in Kayardild is also interesting because many morphological patterns in the language are by their nature open to multiple analyses. Particularly significant in this respect is the abundance of morphological exponents that are polyfunctional, an issue to which we return in Sect. 3.1.

\subsection{Claim and outline}

Our central claim will be that, contrary to the analyses by both Evans (1995a) and Round (2009, 2013), Kayardild does not have two TAM features. Rather, measured against a range of criteria, an analysis based on a single TAM feature is the better motivated alternative. It will be important to be clear about our terms. By a feature we mean a category of grammatical meaning, such as NUMBER. A feature comprises a discrete class of contrasting values, such as SINGULAR, PLURAL, DUAL and so on. For clarity, we use SMALL CAPITALS AND BOLD for features and SMALL CAPITALS for their values.

The paper is structured as follows. We begin by foregrounding the key theoretical point, the logic of differentiating features (Sect. 2). We then outline previous analyses of Kayardild TAM in Sect. 3, taking the opportunity to explain the essentials of the system and to elucidate why we need to go beyond current accounts. This leads naturally to a review of the evidence, the results of which we summarize in Sect. 3, with 
Table 1 Forms for Russian devuška 'girl' and mal'čik 'boy'

\begin{tabular}{|c|c|c|c|c|}
\hline & SINGULAR & PLURAL & SINGULAR & PLURAL \\
\hline NOMINATIVE & devuška & devuški & mal'čik & mal'čiki \\
\hline ACCUSATIVE & devušku & devušek & mal’čika & mal’čikov \\
\hline GENITIVE & devuški & devušek & mal’čika & mal'čikov \\
\hline DATIVE & devuške & devuškam & mal'čiku & mal’čikam \\
\hline INSTRUMENTAL & devuškoj & devuškami & mal’čikom & mal’čikami \\
\hline LOCATIVE & devuške & devuškax & mal’čcike & mal’čikax \\
\hline
\end{tabular}

detail provided in the Appendix. We then bring the core theoretical concern together with our empirical material, to demonstrate how and why a reanalysis of Kayardild TAM is warranted. We do this based on our criteria for differentiating features, as we consider in turn: orthogonality (Sect. 4), compositionality (Sect. 5), licensing in clause types (Sect. 6), distribution within the clause (Sect. 7) and exponence (Sect. 8). Finally, we offer conclusions both on TAM in Kayardild and on its significance for the theory of feature systems (Sect. 9).

\section{The logic of differentiating features}

At this initial point, it is worth asking why we use features, and how we determine the number of features and of their values. This will provide the basis for debating the best analysis of Kayardild TAM.

\subsection{Reasons for differentiating one feature from another}

Let us take a simple example to clarify the central issues. Consider the paradigm of two types of Russian noun in Table 1.

What are the claims inherent in this layout, and how do we justify them? We generally assume that there is a difference between lexical meaning and more abstract grammatical meaning. We need rather specific, concrete information to learn the appropriate use of devuška 'girl' and mal'čik 'boy'. On the other hand, the choice between devuška 'girl' and devuški 'girls' is based on more abstract grammatical meaning. We model this using the feature NUMBER, with the values SINGULAR and PLURAL. The choice between SINGULAR and PLURAL cross-cuts the choice based on lexical meaning; they are different types of information. Thus if we learn a new noun, we do not need to relearn the difference between SINGULAR and PLURAL for it. We say, then, that NUMBER is orthogonal to lexical meaning, and we model it with a feature. Thus devuška 'girl' and devuški 'girls' are forms of the same lexeme, and they vary for values of NUMBER. ${ }^{2}$

Besides NUMBER, Russian nouns also make distinctions of CASE. These case distinctions are orthogonal to lexical meaning: if we know what devuška 'girl' means,

\footnotetext{
${ }^{2}$ We recognize that NUMBER is not fully orthogonal to lexical meaning: not all nouns have a plural, though there are established regularities as to which these are likely to be in a given language (Corbett 2000: 5488).
} 
and we know the circumstances in which the GENITIVE is appropriate in Russian, then we know when to use the GENITIVE of devuška 'girl'. Most important for us, just as NUMBER and CASE are both orthogonal to lexical meaning, so they are orthogonal to each other. That is, each CASE value is found in each NUMBER value, and each NUMBER value is found in each CASE value. ${ }^{3}$ It is evident that the representation in Table 1 makes sense: the alternative, suggesting that there is a single feature with twelve values, would be uneconomical, and would miss important generalizations of several kinds, which we mention now.

That the features are orthogonal to each other is reflected first in semantics, where we find (in the canonical instance) compositionality. That is to say, given the lexical semantics of a lexeme, and the characterization of the feature values in its feature specification, we can predict the meaning of the whole. That is, if we know what devuška means, and we know the grammatical meaning of PLURAL and of DATIVE, we know the meaning of devušk-am ('girl-PL.DAT'). ${ }^{4}$

A further aspect of the distinctness of the features NUMBER and CASE in the Russian nominal system is that they are subject to different rules. Thus Russian verbs agree with their subject in NUMBER, but not CASE. Conversely, they govern CASE, as do prepositions, and they do so irrespective of NUMBER. That is, when we say that a preposition governs a particular case value in Russian (e.g. INSTRUMENTAL) we need make no reference to number: it will govern the INSTRUMENTAL whether the noun is SINGULAR or PLURAL. 5

We should now consider the issue of exponents. The different forms of the lexemes in Table 1 can be distinguished in terms of their exponents. But while we can distinguish, say, the GENITIVE SINGULAR from the DATIVE SINGULAR in Russian, we cannot pull apart CASE and NUMBER. We cannot point to the expression of GENITIVE or DATIVE. Case values in Russian are realized cumulatively with number values. If they could be separated (as happens in languages like Turkish), that would further strengthen the analysis in terms of two distinct features, since the differences in grammatical meaning would be reflected straightforwardly in different forms. ${ }^{6}$

A final type of argument in favour of the analysis of CASE and NUMBER as distinct features in Russian comes from typology. We have seen instances like the NUMBER feature of Russian in a variety of languages, with or without a CASE feature. Equally we have seen other CASE features like that of Russian, with or without a NUMBER

\footnotetext{
${ }^{3}$ There is more to be said about case and number in Russian, since there are additional, less straightforward case values; for the detail, see Corbett (2012: 200-222).

${ }^{4}$ Of course, the meaning of the PLURAL, for instance, is not always fully predictable. While lexical and grammatical meaning do not intersect perfectly, the established approach in linguistics seems right here.

${ }^{5}$ There are instances in the literature where a case value appears to depend on the number value; the interest which these arouse serves to demonstrate the strength of the expectation that this should not occur. See Corbett (2010) for an analysis of the famous example of Latvian.

${ }^{6} \mathrm{Not}$ all the forms in Table 6 are distinct. Some that are identical in form have different featural descriptions; for instance, in the second paradigm the form mal čika is both ACCUSATIVE SINGULAR and GENITIVE SINGULAR of mal'čik 'boy'. This is an instance of syncretism, the use of a single form for more than one function. The assumption which prompts both these non-obvious mappings between the forms and their specifications is the principle that syntax is 'morphology free'. We aim for simple rules of syntax, referring to featural specifications such as ACCUSATIVE, not rules which have access to the way in which such specifications are realized for particular nouns.
} 
feature. And indeed, there are several languages with NUMBER and CASE interacting in a way similar to that of Russian. The typological perspective is invaluable, and helps us avoid suggesting a novel analysis for something that is typologically well-established. Nevertheless, we also need to guard against the danger of forcing a system into a familiar type and missing its particular interest.

Our theoretical reason for pursuing Kayardild TAM further is the general point that having two features of the same type is rare. We are used to finding systems of different types (like CASE and NUMBER). Similarly we know that a particular feature may be present or absent (many languages have case features and many do not). But it is unusual to find a language with two concurrent features of the same type. To take the argument further, we consider one area where concurrent features in fact have been proposed rather frequently.

\subsection{Deceptive exponence: when one feature masquerades as two}

There is one linguistic area, where proposals for concurrent features were made in various accounts, and where a careful argument was then made against them. Languages of Australia have often been analysed in terms of 'split ergativity', according to which there are two concurrent case features; for instance, different systems may be suggested for pronouns and nouns. In an important paper, Goddard (1982: 167) claims that 'the common belief that a typical Australian language has two case systems co-existing within it is mistaken'.

To get to the issues involved we will look at the case marking of subjects and direct objects in Guugu Yimidhirr (Pama-Nyungan), a language which Goddard mentions though it is not one that he analyses. The data are from Haviland (1979), discussed in Baerman et al. (2005: 42-45) and in Corbett (2012: 181-184). Haviland treats subject and object pronouns as distinguishing NOMINATIVE and ACCUSATIVE values of what we might call CASEP (pronominal case). The NOMINATIVE is used for the subject of transitive and intransitive verbs as in (1), (2), and the ACCUSATIVE for the direct object as in (1).

\section{Guugu Yimidhirr}

(1) Ngayu nhinaan yiimuun gunda-1

1SG.NOM 2SG.ACC this.ERG ${ }^{7}$ hit-NON_PST

'I'll hit you with this (thing I have here).'

(Haviland 1979: 73)

$$
\begin{aligned}
& \text { Nyundu nhaa-wal a! } \\
& \text { 2SG.NOM see-IMP RDP } \\
& \text { 'You keep on looking.' }
\end{aligned}
$$

(Haviland 1979: 84)

Nouns and demonstratives however are analysed by Haviland as distinguishing ERGATIVE and ABSOLUTIVE values of what we might call CASEN (nominal case).

\footnotetext{
${ }^{7}$ Haviland (1979: 73) glosses this as instrumental. However, in Guugu Yimidhirr the INSTRUMENTAL is always identical to the ERGATIVE (1979: 47); we gloss it as ERGATIVE. This is because giving two case value labels to a form which never distinguishes them, sometimes called 'absolute syncretism', confuses syntactic function with morphological realization and we wish to avoid this.

${ }^{8}$ Reduplication (here partial) is indicated by $\sim$ in the Leipzig Glossing Rules.
} 
Table 2 Guugu Yimidhirr as two CASE features

\begin{tabular}{|c|c|c|}
\hline CASEP & \multicolumn{2}{|l|}{ CASEN } \\
\hline \multirow{2}{*}{ NOMINATIVE } & ERGATIVE & Transitive subject \\
\hline & \multirow{2}{*}{ ABSOLUTIVE } & Intransitive subject \\
\hline ACCUSATIVE & & Direct object \\
\hline
\end{tabular}

When a noun appears in the subject noun phrase of a transitive verb, its case value is ERGATIVE, as in (3). When a noun is in an intransitive subject or direct object, it is ABSOLUTIVE, as in the first and second clauses of (4) respectively.

Guugu Yimidhirr

(3) Gabirr-inh nhaamuun nganhi bulii-ma-ni. girl-ERG that.ERG 1SG.ACC fall-CAUS-PST 'That girl made me fall.'

(Haviland 1979: 100)

(4) Buligi gada-y, nyulu nhaayun gunda-y. bullock[ABS] come-PST 3SG.NOM that.ABS kill-PST 'The bullock came and he killed it.'

(Haviland 1979: 73)

Given just the pronouns, we could analyse Guugu Yimidhirr as having a NOMINATIVEACCUSATIVE system of CASE. With just the evidence of nouns we would say that it was ERGATIVE-ABSOLUTIVE. As noted above, systems where both occur concurrently are often termed systems of 'split ergativity', and they may appear to involve the presence of two concurrent CASE features. Thus in Guugu Yimidhirr, CASEP is realized on pronouns and distinguishes the values NOMINATIVE and ACCUSATIVE, while CASEN on nouns distinguishes different values, ERGATIVE and ABSOLUTIVE. Moreover, correspondences between values of the two concurrent features are not one-to-one, as shown in Table 2.

According to this analysis, the syntax-morphology interface is somewhat complex. The verb, for example, would need either to 'peek' ahead to see the part of speech of its arguments in order to determine which CASE feature and value to assign, or it would always assign both CASEP and CASEN, though only one of those two features would ever be realized on any given word.

An alternative analysis involves treating Australian languages like most other languages of the world with CASE features. This is what Goddard (1982) recommends. If we have just one CASE feature for Guugu Yimidhirr, we say that an intransitive verb assigns to its subject a value of CASE which we may label NOMINATIVEABSOLUTIVE, ${ }^{9}$ for instance, ngayu 'I' or buligi 'bullock'. A transitive verb assigns CASE:ERGATIVE to its subject (for instance, ngayu 'I' or gabirrinh 'girl') and CASE:ACCUSATIVE to its object (for instance, nganhi 'I' and nhaayun 'that'). Consequently, we are dealing with three distinct values of just one CASE feature, ${ }^{10}$ as in Table 3.

\footnotetext{
${ }^{9}$ This label is mnemonic; we could label the values $1,2,3$ and so on.

${ }^{10}$ Guugu Yimidhirr also has several additional case values, which would be shared if we had two features.
} 
Table 3 Guugu Yimidhirr as a single CASE feature; also indicating syncretism across values, on pronouns and full nouns

\begin{tabular}{|c|c|c|}
\hline \multirow[t]{2}{*}{ CASE } & \multicolumn{2}{|l|}{ Syncretism on } \\
\hline & pronouns full nouns & \\
\hline ERGATIVE & & Transitive subject \\
\hline NOMINATIVE-ABSOLUTIVE & & Intransitive subject \\
\hline ACCUSATIVE & & Direct object \\
\hline
\end{tabular}

There are additional facts which support this analysis, of which we mention one. In Guugu Yimidhirr, noun phrases referring to animates normally include a pronoun in initial position, even where there is also a full nominal, as in (5).

Guugu Yimidhirr

[Nyulu bidha-al NP] [warrbi NP] dumbi
3SG.NOM child-ERG axe[ABS] break.PST (glossing: two features)
3SG.ERG child-ERG axe[ACC] break.PST (glossing: one feature)
'The child broke the axe.'
(Haviland 1979: 101)

The combination of forms in the initial noun phrase makes an analysis with a single CASE feature more economical: the elements of the noun phrase are inflected for the same, single morphosyntactic feature.

A point that we wish to make here is that although there are sound reasons to reject the two-feature analysis of CASE in languages such as Guugu Yimidhirr, there are reasons why it was proposed in the first place which are worth noting. If we look at Table 2, we see that the analysis in terms of two features (CASEP and CASEN) and their values does two things. First, it hugs tightly to the contours of syncretism in the vertical direction: where two cells share their exponent, the analysis assumes that they do so because they share their feature value. Goddard, however, emphasizes that Australian case systems are just like any other inflectional system; they can exhibit syncretism which obscures the underlying grid of feature values. Consequently, to reach a valid analysis, evidence beyond mere exponence must be given weight. Second, the two-feature analysis interprets the divergence in syncretism between pronouns and full nouns as due to two distinct features, whose values fail to correspond one-to-one. Again, the two-feature analysis overly attributes characteristics of exponence to the underlying feature system; other evidence must be weighed before concluding that divergent syncretism across two word (or stem) classes is a symptom of the presence of distinct features. ${ }^{11}$ What we see here, is that once a range of factors have been weighed up, an analysis in terms of one feature may emerge as the most compelling, even when exponence per se lends it little direct support.

\footnotetext{
${ }^{11}$ We should also consider patterns of divergent syncretism within the same word. We would expect it to be harder to demonstrate concurrent systems here. See Evans (2015: 544-552) for interesting discussion of the verbal morphology of Nen, where there are different patterns of syncretism within the prefixes and suffixes, but it proves impossible to maintain an analysis in which they are distinct concurrent systems.
} 


\subsection{Two features or one, from the evidence}

Having said that finding two features of the same type is unusual, and that certain suggested systems are better analysed in another way, we do not wish to imply that concurrent systems are impossible. Rather we are now ready to weigh up the evidence for Kayardild TAM. Does it support an analysis broadly in line with Evans (1995a) and Round (2013), in terms of two TAM features, or an analysis in terms of just one? In Sects. 4-8 we will do this by assessing the evidence from five key properties of the Kayardild TAM system: we examine the orthogonality of features in Sect. 4; semantic compositionality in Sect. 5; licensing of TAM types in various clause structures in Sect. 6; the distribution of TAM inflection across smaller clausal constituents in Sect. 7; and exponence and syncretism in Sect. 8.

\section{Previous accounts of TAM in Kayardild}

We turn now to Kayardild and its TAM system. In Sect. 3.1 we begin with a discussion of morphological polyfunctionality and its central place in any analysis of Kayardild morphology. Then we outline the accounts of TAM in Kayardild due to Evans (1995a) in Sect. 3.2 and Round (2013) in Sect. 3.3, Kayardild's three morphosyntactic clause structures in Sect. 3.4, and the treatment of polarity by Evans and Round in Sect. 3.5. We summarize the points of consensus in these analyses in Sect. 3.6, and in Sect. 3.7 we detail reasons to go further. As we shall see, the validity of certain aspects of previous accounts could be clarified by additional empirical data. Consequently, we conducted a corpus study to this effect. Results are summarized in Sect. 3.8, and details appear in the Appendix. At the conclusion of Sect. 3 we will have all the essentials for our central analytical and theoretical inquiry in Sects. 4-8. (Readers who require the barest outline only may go straight to Sect. 3.6.)

\subsection{Polyfunctionality in Kayardild morphology}

Polyfunctionality of morphological formatives is abundant in Kayardild, and presents two analytic challenges. First, one must account for why clusters of forms all share multiple functions, or equally, why clusters of functions share multiple forms; this challenge pertains to the analysis of the morphological system as a whole. Second, when considering individual utterances, and thus being confronted with a given instance of a form, one must decide which function out of a cluster of possibilities it fulfills.

With respect to analysing the system as a whole, Evans (1995a), following Dench and Evans (1988), handles the polyfunctionality of morphological exponents primarily by positing the existence of several, distinctly different, functions of CASE, where 'CASE' assumes the status of an umbrella concept. For example, the marker $-(k) u((r) u)$ is analysed as a marker of the PROPRIETIVE value of CASE. The several functions of PROPRIETIVE CASE are the ADNOMINAL PROPRIETIVE which relates a DP to another DP, the RELATIONAL PROPRIETIVE which relates a DP to its clause, and the MODAL PROPRIETIVE which conveys TAM semantics marked primarily on 
nominals. ${ }^{12}$ Likewise, the OBLIQUE CASE marker -inja/-ntha has functions that are RELATIONAL, relating DP to clause; MODAL, conveying TAM semantics; or COMPLEMENTIZING, relating clause to clause. In a sense then, each of the various functions of CASE operates as a distinct morphosyntactic feature with its own semanticogrammatical domain and its own set of values. However, when we look across these morphosyntactic features, we repeatedly find values with labels in common (such as PROPRIETIVE, found as a value of ADNOMINAL CASE, RELATIONAL CASE and MODAL CASE), and moreover, such values with a shared label have shared exponents. In this manner, Evans (1995a) captures unity of form including diverse allomorphy, crossed with diversity of function, through an umbrella notion of CASE. ${ }^{13,14}$

Notwithstanding the mileage which Evans gets from this construal of CASE, a wrinkle in the analysis is its handling of VERBAL TAM, henceforth TAMV. Recall that the success of the umbrella notion of CASE is that it captures commonalities of form which range across a diversity of function. In Evans (1995a), TAMV is Kayardild's second TAM feature. TAMV is marked primarily on verbs, and like MODAL CASE it functions semantically to signal TAM categories. Moreover, like all of the various functions of CASE, TAMV employs exponents such as $-(k) u((r) u)$ and -inja, with allomorph sets which are the same as those used in the polyfunctional CASE system. At face value then, it would appear only logical to incorporate TAMV as yet another function under the umbrella of CASE. However, doing so would produce an anomalous result, according to which Kayardild would exhibit profusely polyfunctional CASE, yet have no TENSE at all. Thus we see a tension in Evans' analysis of Kayardild. The umbrella notion of CASE serves the purpose of accounting for polyfunctional forms, yet paradoxically, extending CASE to Kayardild's full range of polyfunctionality would lead to a situation in which even tense would be a function of CASE. ${ }^{15}$ Evans (1995a: 255) elects to keep TAMV separate from CASE, even though its values share the same commonalities of form that justify the united analysis of CASE. (See Round 2013: 181-189 for discussion of further tensions in the system.)

Round $(2009,2011,2013,2015)$ argues that forms such as $-(k) u((r) u)$ and -injal -ntha belong neither to 'CASE' nor 'TAM' categories per se, but to categories of pure morphology, which Aronoff (1994) terms morphomes. These morphomic categories, which are units of analysis unto themselves, then relate on the one hand to sets of allomorphs and on the other hand to sets of morphosyntactic feature values. These feature values include Kayardild's two TAM features, its complementization features, and CASE (now construed narrowly, as a relation between DPs and superordinate constituents). Under this analysis, the link between clusters of forms and clusters of functions is always mediated by a shared morphomic category. It is no longer necessary, either to build an umbrella notion of CASE, or to divorce the analysis of

\footnotetext{
${ }^{12}$ See Nordlinger and Sadler (2004a) for TAM marking on nominals in cross-linguistic perspective.

${ }^{13}$ Of course, we are used to case values having different functions, as with the subjective genitive, objective genitive and possessive genitive. Evans gathers much more diverse functions under the notion CASE.

${ }^{14}$ For a formal implementation of Evans' system in Lexical Function Grammar, see Nordlinger (1998), Nordlinger and Sadler (2004b).

${ }^{15}$ For an analogous argument on the attempt to incorporate person into gender in Archi, see Corbett (2012: 239-251) and Baerman and Corbett (2013).
} 
tense from the remainder of the system. It also allows us to discuss polyfunctionality in a manner which treats Kayardild's various morphosyntactic features more evenly.

Turning now to the second point, the interpretation of individual utterances, it is significant for our present concerns that polyfunctionality of morphological forms can lead in certain instances to an ambiguity of analysis in which multiple analyses are viable. For example, in a particular sentence, a marker $-(k) u((r) u)$ might plausibly be interpreted either as an exponent of a CASE value, or of a TAM value. As we will see, this can influence our picture of the TAM system itself, once we scrutinize clause types where the stock of putative tokens is small and arguably ambiguous.

\subsection{TAM in Evans (1995a)}

Evans (1995a) posits two TAM features for most clause types in Kayardild. A typical example is (6).

$$
\begin{aligned}
& \text { Ngada kurri-nang-ku mala-wu (balmbi-wu). } \\
& \text { 1SG.NOM see-NEG-POT sea-MPROP tomorrow-MPROP } \\
& \text { 'I won't (be able to) see the sea (tomorrow).' [E404.ex.10-12] }{ }^{16}
\end{aligned}
$$

In (6), the first TAM feature, TAMV, takes the POTENTIAL value (glossed POT) and is marked on the verb. The second TAM feature, MODAL CASE, takes the PROPRIETIVE value, and is marked on the direct object and the adverbial nominal balmbi 'tomorrow'. Evans' MODAL CASE is thus a feature concerned with TAM values, rather than with typical case semantics. Typical case semantics are encoded by RELATIONAL CASE, such as the NOMINATIVE RELATIONAL CASE which appears in (1) on the subject (note that Kayardild does not have any dedicated marker of ACCUSATIVE RELATIONAL CASE). Turning back to the TAM features, we can observe that more generally, values of the TAMV are marked on verbs and on nominals which are inflected for a specific set of so-called 'verbal(izing)' values of RELATIONAL CASE. MODAL CASE appears on direct objects and most other non-subject nominal constituents of the clause (Evans 1995a: 412ff). Example (7) is similar to example (6).

\section{Ngada kurri-nang-ku mala-y (barruntha-y). \\ 1SG.NOM see-NEG-POT sea-MLOC yesterday-MLOC \\ 'I could not see the sea (yesterday).' [E404.ex.10-13]}

Examples (6) and (7) have in common the TAMV value POTENTIAL, while their values of MODAL CASE differ, between PROPRIETIVE in (6) and LOCATIVE in (7). This shows us that the value of MODAL CASE is not fully predictable from the value of TAMV,${ }^{17}$ and thus Evans emphasizes that the two features, TAMV and MODAL CASE, cannot be conflated into one. Example (8) shows that predictability is also lacking in

\footnotetext{
${ }^{16}$ We cite sources of examples as follows: those from Evans (1995a) and Round (2013) are cited as [Epp.ex.ee-ee] and [Rpp.ex.ee-ee] respectively, where pp is page number, ee-ee the original example number; from Round's recordings (Round 2005, 2007), as [Ryyyy-mmm-dd]; from Wurm's (1960) recordings as [W1960]; from Tindale's (1963) recordings as [T1963]; and from Evans' (1982-1998) recordings, as [Eyyyy].

${ }^{17}$ In this section, glossing of examples is after Evans (1995a).
} 
Table 4 TAMV and MODAL CASE values in sentences (6)-(12) after Evans (1995a)

\begin{tabular}{lll}
\hline Sentence, clause & TAMV & MODAL CASE \\
\hline$(6)$ & POTENTIAL & PROPRIETIVE \\
\cline { 2 - 2 }$(7)$ & APPREHENSIVE & POCATIVE \\
$(8)$ & & \\
$(9)$ second clause & DESIDERATIVE & OBLIQUE \\
$(10)$ & HORTATIVE & \\
$(11)$ & & \\
$(12)$ & &
\end{tabular}

the reverse direction: examples (7) and (8) share their MODAL CASE value LOCATIVE, but differ in their values of TAMV, between POTENTIAL in (7) and APPREHENSIVE in (8).
Thararra kali-nyarra wambal-iya, naa-nyarr. ember[NOM] jump-APPR bush-MLOC ${ }^{18}$ burn-APPR '(Look out), the embers are jumping into the bush, it might burn.' [E405.ex.10- 16]

Thus, although there are many specific cases of redundancy, in which one can predict MODAL CASE given the value of TAMV and vice-versa, such predictions are not possible across the board, and in the general case, values of TAMV and MODAL CASE can vary freely (Evans 1995a: 398-406). Additional instances are summarized in Table 4, and illustrated in the sentences that follow.

In (8), (9), (10), the TAMV value is APPREHENSIVE, while the MODAL CASE values vary meaningfully between PROPRIETIVE, LOCATIVE and OBLIQUE.

$$
\begin{aligned}
& \text { Nying-ka ngudi-na wangalk, ngada ngumban-ju } \\
& \text { 2SG-NOM throw-NEG.IMP boomerang[NOM }]^{19} \text { 1SG.NOM 2SG-MPROP } \\
& \text { burldi-nyarr. } \\
& \text { throw-APPR } \\
& \text { 'Don't you throw the boomerang, or I'll throw one at you.' [E205.ex.10-15] }
\end{aligned}
$$

In (10), (11), (12) the MODAL CASE value OBLIQUE remains constant, while TAMV varies between APPREHENSIVE, DESIDERATIVE and HORTATIVE.

$$
\begin{aligned}
& \text { Dathin-a wanku baa-nyarra ngijin-inj. } \\
& \text { that-NOM shark-NOM bite-APPR 1SG-MOBL } \\
& \text { 'That shark might bite me.' [E204.ex.5-20] }
\end{aligned}
$$

\footnotetext{
${ }^{18}$ One might well ask whether the -iya of wambal-iya marks the LOCATIVE RELATIONAL CASE (for locations) or the LOCATIVE MODAL CASE (i.e., TAM). In Kayardild, location nominals generally cannot be marked for both the LOCATIVE RELATIONAL CASE and for TAM, and TAM will always win out (see Round 2013: 146-150). Thus, if we assume that wambal- is a location, and that the clause is truly associated with LOCATIVE MODAL CASE, then we can be sure that the marker -iya is LOCATIVE MODAL CASE. However, this does require the assumption that the TAM value in (8) is indeed the same as in (7), and here we face a case of the kind of ambiguity discussed in Sect. 3.1. See Appendix A.5 for further analysis of these cases, including precisely this sentence, (8).

${ }^{19}$ In Kayardild, direct objects of imperatives take the NOMINATIVE RELATIONAL CASE.
} 
Table 5 Features used in sentence types (6)-(15) after Evans (1995a)

\begin{tabular}{lll}
\hline Sentence, clause & After verb stems & After nominal stems \\
\hline$(6)-(12)$ & TAMV & MODAL CASE \\
$(13)$ & NOMINALIZATION \& PRIVATIVE CASE & LOCATIVE MODAL CASE \\
$(14)$ first clause & CONSEQUENTIAL CASE & CONSEQUENTIAL CASE \\
$(15)$ & NOMINALIZATION & ASSOCIATING CASE \& \\
& & ZERO MODAL CASE \\
\hline
\end{tabular}

Dan-inja nga-l-da jalji-nja wirdi-d. here-MOBL 1-PL-NOM shade-MOBL stay-DES

'We should stay here in the shade.' [E263.ex.7-30]

\author{
Wakatha nguku-ntha yalawu-jinj. \\ sister[NOM] water-MOBL fetch-HORT \\ 'Sister should fetch some water.' [E264.ex.7-36]
}

Let us now mention some additional details. In certain clause types, one or both of Evans' TAM features can be absent, and other features may be used instead. We illustrate this in the following examples, and summarize their usage of features, including combinations other than \{ TAMV and MODAL CASE $\}$, in Table 5.

In (13) the verb is inflectionally nominalized and inflected with the PRIVATIVE CASE and so does not carry TAMV inflections (Evans 1995a: 403-404), though the direct object is still inflected for MODAL CASE, in this instance the LOCATIVE.

\title{
Ngada kurri-n-marri dathin-ki bijarrba-y. \\ 1SG.NOM see-NMLZ-PRIV that-MLOC dugong-MLOC \\ 'I didn't see that dugong.' [E237.ex.9-237]
}

In the first clause of (14) both TAMV and MODAL CASE are absent. The nominalized verb carries a CONSEQUENTIAL CASE marker (and no TAMV), as does the direct object which therefore carries no MODAL CASE (Evans 1995a: 480).

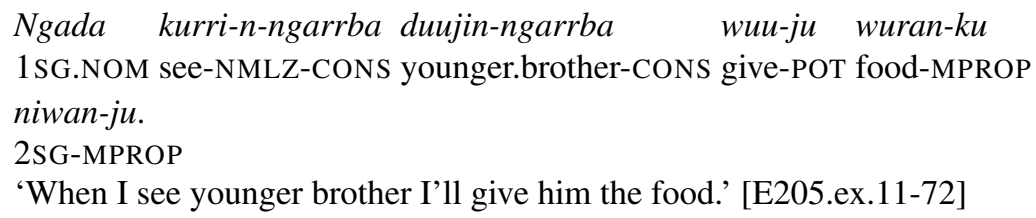

In (15) the verb is nominalized and the direct object is inflected with the OBLIQUE ASSOCIATING CASE. Following Dench and Evans (1988), ASSOCIATING CASE is analysed in Evans (1995a) as a CASE function distinct from MODAL CASE; in (15) MODAL CASE takes a 'ZERO' value. ${ }^{20}$

\footnotetext{
${ }^{20}$ In contrast to sentences (13) and (14), Evans' interpretation of sentences such as (15) is that the verbal nominalizer does carry TAM information (Evans 1995a: 253-257, 266). The object has what Evans calls a 'ZERO' MODAL CASE, i.e., a MODAL CASE value whose exponent is null (Evans 1995a: 399, fn. 1, 472), though see also Evans (1995a: 266) for a different formulation.
} 
Ni-ya kala-n-da thungal-inj.

3SG-NOM cut-NMLZ-NOM tree-AOBL

'(S)he is cutting the tree.' [E452.ex.11-1]

In sum, Evans posits two TAM features, TAMV whose values are listed in (16) and MODAL CASE whose values are listed in (17), and these can be varied independently 'to some extent' (Evans 1995a: 405).

values of TAMV (Evans 1995a)

ACTUAL, APPREHENSIVE, DESIDERATIVE, DIRECTED, HORTATIVE, IMMEDIATE, IMPERATIVE, NOMINALIZATION, PAST (referred to as ALMOST in the negative, compare Sect. 5.1), POTENTIAL, PRECONDITION

values of MODAL CASE (Evans 1995a)

MODAL ABLATIVE (also referred to as marking 'PRIOR MODALITY'), MODAL ALLATIVE, MODAL LOCATIVE (also, 'INSTANTIATED MODALITY'), MODAL OBLIQUE (also, 'EMOTIVE MODALITY'), MODAL PROPRIETIVE (also, 'FUTURE MODALITY'), ZERO MODAL CASE (also, 'ZERO MODALITY')

Somewhat exceptional are clause types in which either or both of TAMV or MODAL CASE are absent and/or some other kind of marking appears on the constituents where typically TAMV or MODAL CASE are found; these include verbal NOMINALIZATION, on its own or with PRIVATIVE CASE, in place of TAMV; CONSEQUENTIAL CASE in place of both TAMV and MODAL CASE; and ASSOCIATING CASE in addition to a ZERO MODAL CASE.

\subsection{TAM in Round (2013)}

Like Evans, Round (2013) posits two TAM features in Kayardild, and the analyses are broadly similar. One difference is that Round (2013) also incorporates sentences such as (13)-(15) above into the core TAM system. Having noted the high degree of polyfunctionality in Kayardild's morphological exponents, Round (2013: 73-74, 182-184) argues that there is little reason to interpret the markers - $n$-ngarrba, in (14) for example, literally as nominalization plus CASE:CONSEQUENTIAL. Rather, notwithstanding their appearance elsewhere in the system with other functions, they function in (14) precisely as a composite marker of a single TAM value. This move allows Round (2013) to bring all of Kayardild's clause types under a uniform description in terms of two TAM features, both of which are therefore something of an expansion of Evans' TAMV and MODAL CASE.

As part of the move away from the use of 'CASE' as an umbrella concept for handling polyfunctionality, Round relabels some of Kayardild's morphosyntactic features, relative to Evans' analysis: Round's CASE feature is for case in the narrow sense (corresponding to Evans' ADNOMIMAL and RELATIONAL CASE), and Round's TAM features are termed THEMATIC TAM or TAMT (an expansion of Evans' TAMV) and ATHEMATIC TAM or TAMA (an expansion of Evans' MODAL CASE). The terms 'thematic' and 'athematic' refer to types of morphological stems which condition a choice between the appearance of TAMT or TAMV inflection, as follows. 
In Kayardild morphotactics, TAM suffixes appear directly on lexical verbal stems, and outside of CASE marking, if there is any, on nominal stems. When inflecting for the TAM values associated with a given clause, stems that get inflected for TAM will license (or subcategorize for) either TAMT inflection or TAMA inflection, but not both. (When clauses are embedded, a word which exhibits Suffixaufnahme may carry up to one TAM inflection for each clause, Round 2013: 118-29.) Thematic stems, which license inflection for TAMT, all end morphologically with a 'thematic' element, phonologically /t/ or /c/ at the underlying level (Round 2013: 15-22). ${ }^{21}$ These include lexical verb stems, which end with a thematic element in their lexical representation; nominal stems consisting of a base plus the thematic-final markers of what Evans (1995a) had termed verbal(izing) CASE inflections; and both nominal and verbal stems consisting of a base plus the thematic-final markers of INCIPIENT TAM inflections, a rare kind of TAM marking identified in Round's corpus of spontaneous speech (Round 2013: 103). Athematic stems, which license inflection for TAMA, are simply those stems which are not thematic. This analysis of TAM licensing differs from Evans (1995a). In Evans (1995a), thematics are placed inside the inflectional suffix, not the stem, and hence a different device is required to ensure that stems license the correct TAM feature. For Evans the solution is 'categorychanging inflection', which gives rise to mismatches between the syntactic and morphological classes of 'nominal' and 'verbal' words (see Evans 1995a: 90-91, 163, 177-180). Round (2013) demonstrates that for Kayardild such an analysis is not necessary. $^{22}$

Putting this together, Round's glossing of examples such as (18) is in three lines. Below the orthographic form, which is essentially surface-phonemic, appears an underlying phonological string in which morphs are separated by phonological junctures. Segments adjacent to junctures undergo various regular phonological processes, often involving lenitions and deletions (Round 2009, 2013: 13-14), for example in waajarra the underlying cluster / $+\mathrm{n} /$ surfaces as just /c/ (orthographic j). ${ }^{23}$ The lowest line in (18) gives semantic glosses for lexical stems and morphosyntactic feature values such as CASE:DATIVE (glossed DAT), TAMT:PAST (PST), TAMA:PRIOR (PRIOR). The middle line glosses morphomic categories, many of which have mnemonic labels such as $\mu \mathrm{DAT}$ 'morphomic dative' ${ }^{24}$ Also appearing on that line is a word final morphomic element $\mathrm{T}$, the 'termination', which appears as a meaningless piece of morphological form at the end of all Kayardild words (Round 2013: 13-14, Round 2016); because the termination lacks a meaning, it receives no gloss on the bottom line. Braces indicate one-to-many mappings from morphosyntactic feature values to morphomic elements, as when the

\footnotetext{
${ }^{21} \mathrm{The} / \mathrm{t} / \mathrm{or} / \mathrm{c} / \mathrm{consonant}$ is typically visible in the surface phonological form, but will delete when followed by certain suffix-initial consonants, according to the regular rules of Kayardild phonology (Round 2013: 17).

${ }^{22}$ Indeed, the coherence of the category-mismatch analysis breaks down once the most complex corners of the morphological system are taken into account (Round 2013: 187-189).

${ }^{23}$ This clarification of Kayardild's phonological processes (Round 2009) allowed for the sharpening of several morphological arguments, such as the status of thematics (Round 2009, 2013: 15-23).

${ }^{24}$ Some labels, such as $\mu$ CONS, bear a diacritic above the $\mu$. This relates to morphomic conditioning of phonological allomorphs, on which see Round (2013: 30-33).
} 
single feature value CASE:DATIVE, glossed $\{\mathrm{DAT}\}$, maps to the morphomic string $\{\mu \mathrm{DAT}-\mathrm{TH}\}$.

\begin{tabular}{|c|c|c|}
\hline Niya & waajarra & wangarrina \\
\hline ni-a & wa:-c+nara- $\varnothing$ & wayar+ki-naa- $\varnothing$ \\
\hline $3 \mathrm{SG}-\mathrm{T}$ & $\{$ sing-J $\}-\mu \tilde{C O N S}-\mathrm{T}$ & song- $\{\mu \mathrm{LOC}-\tilde{\mu} \mathrm{ABL}\}-\mathrm{T}$ \\
\hline $3 \mathrm{SG}$ & $\{$ sing $\}-P S T$ & song- $\{$ PRIOR $\}$ \\
\hline \multicolumn{3}{|c|}{ ngumbanmarutharra } \\
\hline \multicolumn{2}{|c|}{ рuy+pan-maju-t+yara- $\varnothing$} & tapucu-mału-t+nara- $\varnothing$ \\
\hline $\multicolumn{2}{|c|}{2 \mathrm{SG}-\mu \mathrm{POSS}}-\{\mu \mathrm{DAT}-\mathrm{TH}\}-\mu \mathrm{CONS}^{-T}$ & elder.brother- $\{\mu \mathrm{DAT}-\mathrm{TH}\}-\mu$ CONS-T \\
\hline $\multicolumn{3}{|c|}{2 \mathrm{SG}}-\{\mathrm{DAT}\}-\mathrm{PST}$ \\
\hline
\end{tabular}

In (18), the TAM features associated with the clause are TAMT:PAST and TAMA: PRIOR. Inflection for TAMT:PAST is licensed on the lexical verb stem waaj'sing', and on the nominal stems ngumbanmaruth- 'my (DAT)' and thabujumaruth'brother(DAT)', which are formed by inflecting lexical stems with the DATIVE CASE. TAMT inflection is licensed on exactly those stems, because both the lexical verb stem waaj and the DATIVE CASE marker end morphomically with a thematic element, glossed TH or J on the morphomic line. In contrast, inflection for TAMA:PRIOR is licensed on the athematic stem wangarr- 'song'. The subject niya 'she' is inflected neither for TAMT nor TAMA, for reasons we turn to next.

In a Kayardild clause, every thematic stem will inflect for the clause's TAMT value. However, of the athematic stems, only those in certain DPs will inflect for TAMA (Round 2013: 113-131). Put briefly, among all of the semantically and grammatically defined DP types in Kayardild, only a proper subset can inflect for each TAMA value. Moreover, there are only three such subsets which a given TAMA value will be associated with, and those subsets are nested one within another. For example, those TAMA values with the most restricted inflectional distribution appear only on a small group of object-like DPs (let us call these DPs 'group A'), plus an additional small group, B, of adverbial DPs. The next-most restricted TAMA values will inflect DPs in groups $\mathrm{A}$ and $\mathrm{B}$, plus another small group, C, of additional adverbial DPs; and those TAMA values with the broadest distribution inflect DPs in groups A, B and C, plus another small group, D, of yet other adverbial DPs. Finally, there remains a further group, E, of other adverbial DPs, as well as subjects, topics and focus DPs which are never inflected for TAMA. Round (2013: 78-129) observes that essentially, the system is organized according to a constituent structure as shown in (19), in which various values of TAMA associate with, and take scope over, one of the three 'VP' nodes, ${ }^{25}$ with respect to which various groups of DPs are situated as daughters of $\mathrm{V}_{\alpha}^{\prime}, \mathrm{VP}_{\beta}, \mathrm{VP}_{\gamma}, \mathrm{VP}_{\delta}$ and $\mathrm{VP}_{\varepsilon} .{ }^{26}$ Other non-TAM features provide similar evidence for yet more constituent structure, shown in (19) as the higher, S-category nodes (Round 2013: 88-96).

\footnotetext{
${ }^{25}$ Evans (1995a: 121) defines his "VP" constituent in similar, inflectional terms.

${ }^{26}$ Group "T" refers to adverb phrases and DPs inflected with thematic CASE values.
} 
(19) Constituent structure describing inflectional distributions

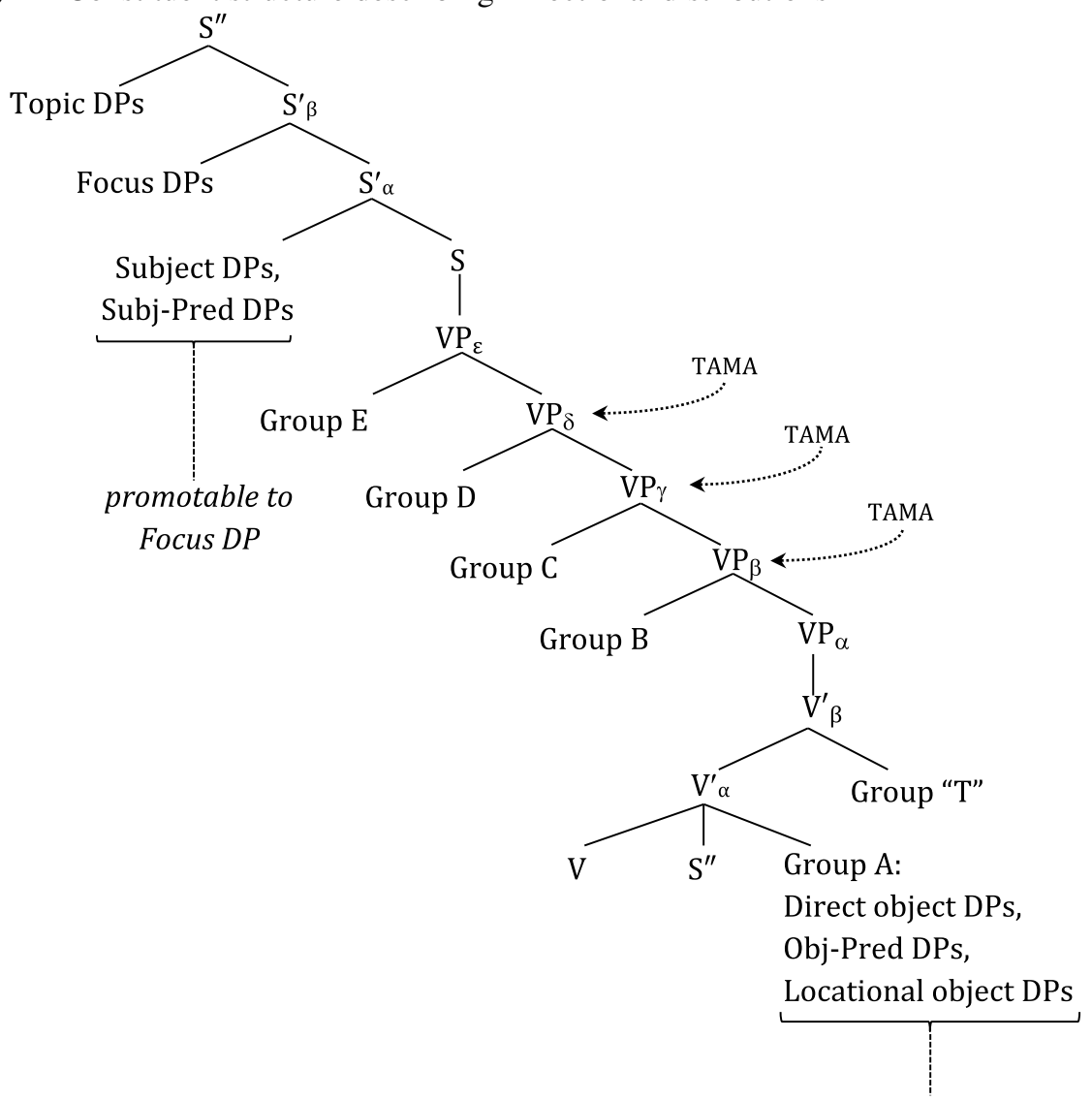

promotable to Focus DP, Topic DP;

also to passive Subject DP / Subj-pred DP

As Round emphasizes, the constituent structure in (19) describes facts of Kayardild inflection; it is intended neither to describe nor to explain surface word order (which is much freer) but rather to furnish a simple formalization of some of Kayardild's most interesting and detailed grammatical facts with respect to inflection and its distribution in the clause. Supporting evidence for the geometry of the constituents labelled 'VP' and their daughters is detailed in Round (2013: Appendix B), and for the $S$ category nodes and their daughters in Round (2013: 8896).

In summary, Round (2013) analyses every clause of Kayardild as involving one value each of two TAM features, TAMA and TAMT, whose distribution in the clause is complex but regular, showing sensitivity to the morphological shape of stems (thematic versus athematic), the specific feature values involved (for TAMA), and an organizational constituent structure as in (19). Lists of the values for Round's TAMT and TAMA features are given at the end of the next section (Sect. 3.4). 


\subsection{TAM in Kayardild's three morphosyntactic clause structures}

Kayardild clauses each have one of three major kinds of morphosyntactic structure (Round 2013: 88-95). There are two kinds of full clause, whose syntactic structure is as shown in (19); and embedded clauses which consist of a $\mathrm{VP}_{\varepsilon}$ node and structure below that. The most commonly occurring of these is a full clause which is uncomplementized, meaning that it is not associated with either of Kayardild's two morphosyntactic complementization features. The other kind of full clause is complementized; it is associated with one or both of Kayardild's two complementization features, ${ }^{27}$ which are realized on most words of the clause (see further Round 2013: 88-96). Of interest for current purposes is that the range of TAM values available for use in each clause type is not identical.

Uncomplementized full clauses exhibit the widest variety of TAM options. The TAM options in complementized full clauses are essentially a proper subset of those in uncomplementized full clauses, though with one caveat. Round $(2013: 115,130)$ shows that the exponent of the default present-like tense on athematic stems has a different syntactic distribution in complementized and uncomplementized clauses. In the former, it appears on all DPs under $\mathrm{VP}_{\gamma}$ and in the latter on all DPs under $\mathrm{VP}_{\beta}$. Consequently, Round posits two distinct values of his TAMA feature, labelled PRESENT and INSTANTIATED respectively, whose associations with VP nodes differs. However, we wish to emphasize an alternative not pursued in Round (2013). Namely, in complementized clauses all TAMA values associate with $\mathrm{VP}_{\gamma} \cdot{ }^{28}$ One could propose, then, that the syntactic-distributional distinctions among TAMA values which are apparent in uncomplementized clauses are simply neutralized in complementized clauses, so that all TAMA associates with $\mathrm{VP}_{\gamma}$. On that account, the distinction between Round's TAMA:PRESENT and TAMA:INSTANTIATED is unnecessary, and one can state rather simply, that the range of TAM types available in complementized clauses is a proper subset of those available in uncomplementized clauses. We provide additional support for this analysis in Appendix A.4.

In embedded VPs, the range of TAM options overlaps only partly with that of the full clauses. Lists of Round's TAMT and TAMA values, and the clause structures which license them are shown in (20) and (21). Clause structures are abbreviated as

\footnotetext{
${ }^{27}$ Round's two features are labelled COMPLEMENTIZATION and SEJUNCT. The former feature associates in the syntax with the node $\mathrm{S}_{\beta}^{\prime}$ in (19) and the latter with $\mathrm{S}_{\alpha}^{\prime}$. All complementized clauses have a COMPLEMENTIZATION feature; only some have SEJUNCT. Both features have just a single value (glossed COMP and SEJ), if they are present at all. Given the level of scrutiny that we apply to Kayardild's two TAM features, one might reasonably ask whether the two complementization features also deserve such attention. To address this briefly, we can state that unlike TAM, the behaviour of the two complementization features is for the most part what we would expect from two features and not one according to the criteria in Sects. $4-8$ below. Namely, their semantic contributions combine compositionally; and they associate with different syntactic constituents $\left(\mathrm{S}_{\beta}^{\prime}{ }_{\beta}\right.$ and $\left.\mathrm{S}^{\prime}{ }_{\alpha}\right)$; they are partly orthogonal, in that a clause may be associated with COMPLEMENTIZATION with or without SEJUNCT (though SEJUNCT always co-occurs with COMPLEMENTIZATION); and they have distinct realizations, with the caveat that when a specific word is associated with both features, it will inflect overtly only for SEJUNCT. For further discussion, see Round (2013: 87-96).

${ }^{28}$ Stated more carefully, all available evidence is consistent with TAMA associating always with $\mathrm{VP}_{\gamma}$. Some TAMA values' exact association is underdetermined by the available data, including data from the corpus we examine in the Appendix.
} 
follows: $\mathrm{u}$ for uncomplementized full clauses, $\mathrm{c}$ for complementized full clauses, and e for embedded VP. Information in (20)-(21) is from Round (2013: 75), modulo our removal of the unnecessary TAMA:PRESENT.

(20) Values of TAMT and the clause structures which license them (Round 2013) ACtuAl $(u)$, ANTECEDEnt $(u, c, e)$, APPREHENSIVE $(u, c)$, DiRECTED $(u, e)$, Desiderative $(u, c)$, HORTATIVE $(u, c)$, IMMEDiATE $(u)$, IMPERATIVE (u), INCIPIENT (e), NONVERIDICAL (u, e), PAST (u, c), POTENTIAL $(\mathrm{u}, \mathrm{c})$, PRECONDITION (u, c), PROGRESSIVE (e), RESULTATIVE (u, e)

(21) Values of TAMA and the clause structures which license them (Round 2013) Antecedent (u, c, e), Continuous (u, e), Directed (u, e), EMotive $(\mathrm{u}, \mathrm{c})$, FUnCTIONAL (e), FUTURE (u, c), INCIPIENT (e), INSTANTIATED $(u, c)$, NEGATORY (u, e), PRECONDITION $(u, c)$, PRIOR $(u, c)$, ZERO $(u, e)$

\subsection{Polarity}

Evans (1995a: 254) and Round (2013: 68) both identify a NEGATIVE inflection, which is typically realized as the marker /-nay/ and is licensed, like Evans' TAMV and Round's TAMT, by all thematic stems in the clause. This is seen in (22), where it appears on the lexical verb stem, and on the two nominal stems inflected with the thematic markers of CASE:COLLATIVE. In (22) as under most conditions, the marker of TAMT, in this case TAMT:POTENTIAL, is linearly ordered after the negation suffix. ${ }^{29}$ We will assume that NEGATIVE is a value of the feature POLARITY.

$$
\begin{aligned}
& \text { Ngada warranangku } \\
& \text { yat-ta wara-c-nan+kuu- } \varnothing \\
& \text { dathinkiiwanangku } \\
& \text { 1SG-T \{go-J }\}-\mu N E G-\mu \text { PROP-T } \\
& 1 \mathrm{SG} \quad\{\text { go }\} \text {-NEG-POT } \\
& \text { that- }\{\mu \mathrm{LLOC}-\mu \mathrm{INCH}-\mathrm{TH}\}-\mu \mathrm{NEG}-\mu \text { PROP-T } \\
& \text { ngilirriiwanangku. } \\
& \text { nilir+ki:-wa-t-nan+kuu- } \varnothing \\
& \text { that- }\{\mu \mathrm{LLOC}-\mu \mathrm{INCH}-\mathrm{TH}\}-\mu \mathrm{NEG}-\mu \text { PROP-T } \\
& \text { that-\{COLL }\}- \text { NEG-POT } \\
& \text { 'I will not go to that cave.' [E163.ex.4-107] }
\end{aligned}
$$$$
\text { tatin+ki:-wa-t-nan+kuu- } \varnothing
$$

The suffix /-nay/ which realizes NEGATIVE undergoes regular phonological processes, including the deletion of its final $/ \mathrm{y} /$ in word final position, as in (18). Sentence (23) is a negative imperative. Unlike most TAMT values, which in the context of NEGATIVE are realized by distinct suffixes, the value TAMT:IMPERATIVE is realized cumulatively with POLARITY:NEGATIVE.

$\begin{array}{llll}\text { Bilarrina } & \text { dathina } & \text { ngukuwa } & \text { wurumanki, } \\ \text { pilari-c-nan- } \varnothing & \text { tatina } & \text { juku-a } & \text { wujuman+ki-a } \\ \text { \{spill-J\}- } \mu \text { NEG-T } & \text { that.T } & \text { water-T } & \text { billy- } \mu \text { LOC-T } \\ \text { \{spill\}-NEG.IMP } & \text { that } & \text { water } & \text { billy-LOC } \\ \text { 'Don't spill that water in the billy can,' [E139.ex.4-17] }\end{array}$

${ }^{29}$ Technically, the negative marker $\mu N E G$ is itself 'thematic', and so licences TAMT inflection to its right, and not TAMA (Round 2013: 234). 
There is one condition under which the negation feature is not realized as underlying /-nay/: TAMT:ACTUAL and POLARITY:NEGATIVE are realized cumulatively as underlying /+wari/, as in (24).

$\begin{array}{lll}\text { Ngada } & \text { kalatharri } & \text { wangalk-i. } \\ \text { jat-ta } & \text { kala-t+wari-a } & \text { wayalk+ki-a } \\ 1 \mathrm{SG}-\mathrm{T} & \{\text { cut-J }\}-\mu \text { PRIV-T } & \text { boomerang- } \mu \text { LOC-T } \\ 1 \mathrm{SG} & \text { \{cut } \text {-NEG.ACT } & \text { boomerang-INS } \\ \text { 'I haven't made a boomerang.' [E257.ex.7-7] }\end{array}$

Only a subset of the total list of TAMT values and TAMA values may co-occur with NEGATIVE POLARITY. For Round's (2013) system, these are as listed in (25), (26).

(25) TAMT values that can co-occur with POLARITY:NEGATIVE

ACTUAL, HORTATIVE, IMMEDIATE, IMPERATIVE, PAST, POTENTIAL, PRECONDITION

not: ANTECEDENT, APPREHENSIVE, DIRECTED, DESIDERATIVE, INCIPIENT, NONVERIDICAL, PROGRESSIVE, RESULTATIVE

(26) TAMA values that can co-occur with POLARITY:NEGATIVE

EMOTIVE, FUTURE, INSTANTIATED, PRECONDITION, PRESENT, PRIOR, ZERO

not: ANTECEDENT, CONTINUOUS, DIRECTED, FUNCTIONAL, INCIPIENT, NEGATORY

Other clause types either lack an inflectional negative counterpart, or make use of a second class of clausal negation strategies which is illustrated in (27)-(30).

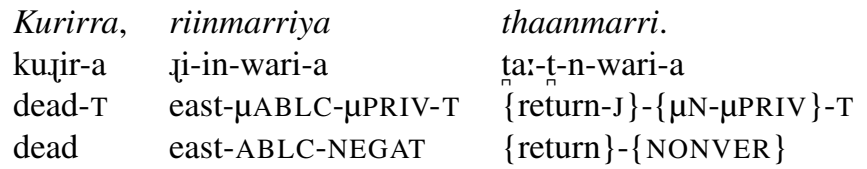

'They were dead, and did not return from the east.' [T1963]

\begin{tabular}{|c|c|c|c|}
\hline Ngada & kurrinmarri & dathinki & bijarrbay. \\
\hline yat-ta & kuri-c-n-wari-a & tatin+ki-a & picarpa+ki-a \\
\hline $1 \mathrm{SG}-\mathrm{T}$ & $\{$ see-J $\}-\{\mu \mathrm{N}-\mu \mathrm{PRIV}\}-\mathrm{T}$ & there- $\mu \mathrm{LOC}-\mathrm{T}$ & dugong- $\mu \mathrm{LOC}-\mathrm{T}$ \\
\hline 1SG & $\begin{array}{l}\{\text { see }\}-\{\text { NONVER }\} \\
\text { see that dugong.' [E275. }\end{array}$ & there-INS & dugong-INS \\
\hline
\end{tabular}

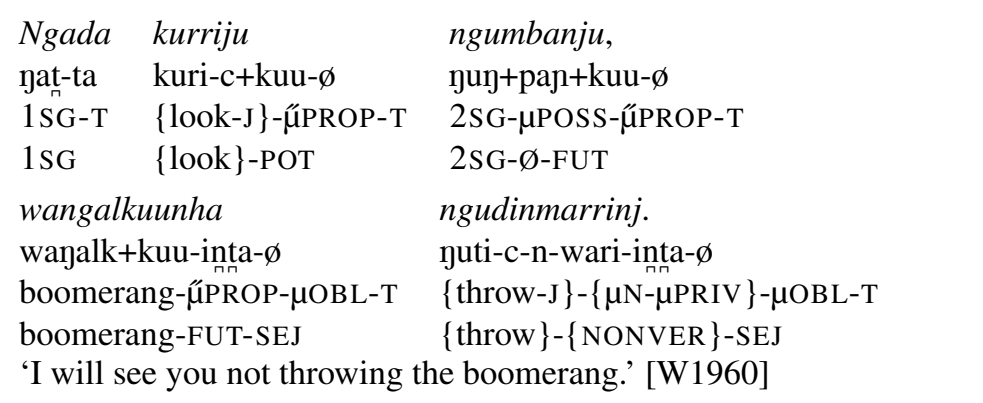


Table 6 TAMT and TAMA values in sentences (27)-(30) after Round (2013)

\begin{tabular}{lll}
\hline Sentence, clause & TAMT & TAMA \\
\hline$(27)$ & NONVERIDICAL & NEGATORY \\
$(28)$ & NONVERIDICAL & INSTANTIATED \\
$(29)$ second clause & NONVERIDICAL & FUTURE \\
$(30)$ & NONVERIDICAL & PRIOR \\
\hline
\end{tabular}

\begin{tabular}{|c|c|c|}
\hline $\begin{array}{l}\text { Nyingka } \\
\text { jin+ka }\end{array}$ & $\begin{array}{l}\text { ngukuna } \\
\text { juku-ki-naa- } \emptyset\end{array}$ & $\begin{array}{l}\text { dalijarrmanmarri? } \\
\text { tali-c-arma-t-n-wari-a }\end{array}$ \\
\hline $2 \mathrm{SG}-\mathrm{T}$ & water- $\{\mu \mathrm{LOC}-\tilde{\mu} \mathrm{ABL}\}-\mathrm{T}$ & $\{$ come-J $\}-\{\mu$ CAUS $-\mathrm{TH}\}-\{\mu \mathrm{N}-\mu \mathrm{PRIV}\}-\mathrm{T}$ \\
\hline $2 \mathrm{SG}$ & water- $\{$ PRIOR $\}-T$ & $\{$ come $\}-\{$ CAUS $\}-\{$ NONVER $\}$ \\
\hline
\end{tabular}

For Evans (1995a), sentences (27)-(30) fall outside of the TAMV system, and exhibit what Evans terms PRIVATIVE NOMINALIZATION of thematic stems (1995a: 373374, 403-404, 475-476). For Round (2013), such sentences figure within the regular TAM system, and as a consequence examples (27)-(30) provide yet more instances of TAMA values varying independently of TAMT, as summarized in Table 6 .

\subsection{Consensus}

The analyses of Kayardild TAM and polarity by Evans (1995a) and Round (2013) are in agreement that most if not all Kayardild clauses are characterizable in terms of two concurrent TAM features. They also agree that most of those values do not stand in a one-to-one relationship, between values of one feature and the other. The minority which do so are listed in (31), following the system of Round (2013). Other values of TAMA and TAMT co-occur with one another in a one-to-many or many-to-many fashion.

One-to-one pairings of TAMA and TAMT values (Round 2013: 75)

TAMA:ANTECEDENT \& TAMT:ANTECEDENT

TAMA:DIRECTED \& TAMT:DIRECTED

TAMA:INCIPIENT \& TAMT:INCIPIENT

TAMA:PRECONDITION \& TAMT:PRECONDITION

For both Evans (1995a) and Round (2013), a NEGATIVE POLARITY value realized on thematic stems can co-occur with certain values of the TAM features. A second set of clausal negation strategies, involving its own distinct marking of thematic stems, and which Round analyses as part of the TAMT system, also combines with multiple TAMA values.

\subsection{Reasons to go further}

Given that there are two detailed studies which include TAM in Kayardild, we should explain why we need to return to this well-rehearsed topic.

The first reason is that there are some unresolved issues regarding the categorization of key data. We observed in Sect. 3.1 that many of Kayardild's morphological markers are polyfunctional, and that as a consequence some sentences are 
amenable to multiple analyses. Since this could become significant in cases where a given clause type is attested only sparsely and ambiguously, we wished to reexamine the Kayardild corpus before proceeding further. Results of our corpus survey are in Sect. 3.8, and details are in the Appendix.

The second reason to delve further is the key point on which the two analyses agree, namely that Kayardild has two concurrent TAM features. If correct, this would be typologically unusual, and it is this which makes us want to revisit the topic. Since this characteristic is rare, we must ensure that an account with two concurrent features does indeed represent the best analysis of Kayardild TAM. If so, we should explore its particular properties carefully. If it turns out not to be so, this is also an important finding. Either way, there are things to be learned from this area of Kayardild which we cannot investigate elsewhere.

\subsection{Corpus study results}

The Appendix contains detailed evidence on several empirical points bearing directly on the question of whether we analyse Kayardild as having one TAM feature or two, and consequently, rehearsing that evidence is the essential next step in the argument. However, the arguments and evidence in the Appendix contain many working parts and some readers may wish to avoid that level of detail, at least on first reading. For those who wish to see the full detail, we are pleased to recommend immersing oneself in the Appendix. For those who would prefer to take us on our word for the moment, the essential points are these: corpus overview in Appendix A.1; in Appendix A.2 the removal of Round's TAMA:NEGATORY value from the inventory of athematic TAM values, on the grounds of evidence from the interface between syntax and inflection; in Appendix A.3 the identification of a feasible reanalysis of NONVERIDCAL as a value of POLARITY rather than TAMT; in Appendix A.4 the simplification of Round's three-way distinction in present tense TAM types to a two-way distinction, after considering evidence from usage and frequency; in Appendix A.5 the simplification of Kayardild's range of apprehensive clause types, from three to two, after identifying more parsimonious alternative analyses; and in Appendix A.6 the identification of a consistently counterfactual usage of the combination of TAMA:INSTANTIATED and TAMT:POTENTIAL. At the end of this process, a revised list of eleven TAMT and fifteen TAMT values is given in (32)-(33). These are the values we will consider in the following sections.

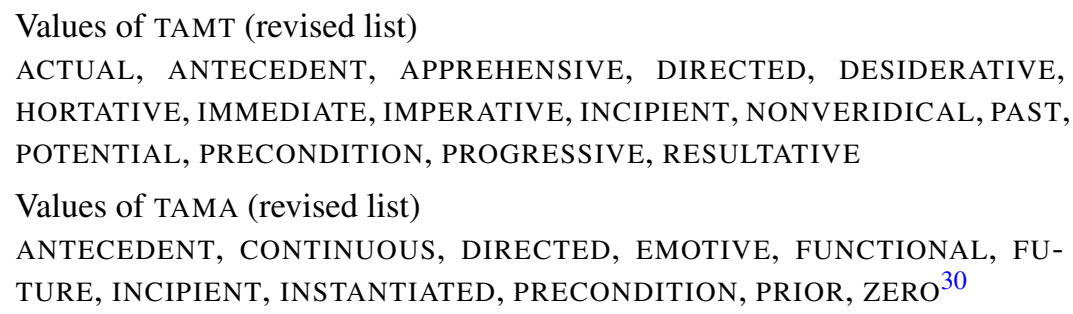

${ }^{30}$ The final value here, which has no overt phonological realization, is labelled ZERO. In Round's
constraint-based analysis of Kayardild's realizational morphology, it is important to make the difference 
Table 7 Co-occurrences of TAMT and TAMA values (in positive polarity clauses)

\begin{tabular}{|c|c|c|c|c|c|c|c|c|c|c|c|}
\hline \multirow[t]{2}{*}{ Thematic TAM } & \multicolumn{11}{|c|}{ Athematic TAM } \\
\hline & FUNC & CONT & EMO & FUT & INS & PRIOR & ZERO & ANTE & DIR & INCIP & PREC \\
\hline PROG & $\checkmark$ & $\checkmark$ & & & & & & & & & \\
\hline DES & & & $\checkmark$ & & & & & & & & \\
\hline HORT & & & $\checkmark$ & & & & & & & & \\
\hline APPR & & & $\checkmark$ & $\checkmark$ & & & & & & & \\
\hline РОТ & & & & $\checkmark$ & $\checkmark$ & & & & & & \\
\hline NONVER & & & & $\checkmark$ & $\checkmark$ & $\checkmark$ & & & & & \\
\hline ACT & & & & & $\checkmark$ & & & & & & \\
\hline IMM & & & & & $\checkmark$ & & & & & & \\
\hline PAST & & & & & & $\checkmark$ & & & & & \\
\hline RES & & & & & & & $\checkmark$ & & & & \\
\hline IMP & & & & & & & $\checkmark$ & & & & \\
\hline ANTE & & & & & & & & $\checkmark$ & & & \\
\hline DIR & & & & & & & & & $\checkmark$ & & \\
\hline INCIP & & & & & & & & & & $\checkmark$ & \\
\hline PREC & & & & & & & & & & & $\checkmark$ \\
\hline
\end{tabular}

\section{Orthogonality of TAM values}

If two features, $\mathbf{F}$ and $\mathbf{G}$ are fully orthogonal, then each value of feature $\mathbf{F}$ will cooccur with each value of $\mathbf{G}$, as was true of CASE and NUMBER in the Russian data presented in Table 1. Conversely, in the limiting case, two non-orthogonal features would have values that only correspond in a one-to-one fashion. In such an instance, we would conclude that the evidence from orthogonality offers little support for the two-feature analysis, and rather, that $\mathbf{F}$ and $\mathbf{G}$ are better analysed as just one feature.

\subsection{Orthogonality of the two TAM features}

Let us apply these notions to the issue of TAM in Kayardild. If Evans and Round are correct in analyzing Kayardild TAM as based on two concurrent features, then all else being equal, we would expect those features to display a high level of orthogonality; a low level of orthogonality would weaken the claim for a two-feature system and favour a one-feature analysis.

In the two-feature analysis of Kayardild TAM, there are eleven values of TAMA and fifteen values of TAMT (if one counts NONVERIDICAL as TAMT, as in (32)). All co-occurrences attested in our corpus are shown in Table 7.

between 'ZERO' TAMA (which blocks the overt realization of TAMT on the same word) and no TAMA at all, which would not do so (Round 2013: 234, fn. 6). One advantage of adopting a one-feature analysis is that the entire apparatus of TAM blocking becomes unnecessary. Rather than requiring TAMA and TAMV to block one another in different ways on different stems, it would suffice to state that a single TAM feature in the general case receives exponence on both stem types (thematic and athematic), and that for some values of the feature one or other stem type carries no overt exponent. 
Table 8 Values in a two-feature versus one-feature TAM system

\begin{tabular}{|c|c|c|c|c|c|c|c|c|c|c|c|}
\hline \multirow[t]{2}{*}{ Thematic TAM } & \multicolumn{11}{|c|}{ AThematic TAM } \\
\hline & FUNC & CONT & EMO & FUT & INS & PRIOR & ZERO & ANTE & DIR & INCIP & PREC \\
\hline PROG & [1] & [2] & & & & & & & & & \\
\hline DES & & & [3] & & & & & & & & \\
\hline HORT & & & [4] & & & & & & & & \\
\hline APPR & & & [5a] & [5b] & & & & & & & \\
\hline РОт & & & & [6] & [7] & & & & & & \\
\hline ACT & & & & & [8] & & & & & & \\
\hline IMM & & & & & [9] & & & & & & \\
\hline PAST & & & & & & [10] & & & & & \\
\hline RES & & & & & & & [11] & & & & \\
\hline IMP & & & & & & & [12] & & & & \\
\hline ANTE & & & & & & & & [13] & & & \\
\hline DIR & & & & & & & & & [14] & & \\
\hline INCIP & & & & & & & & & & [15] & \\
\hline PREC & & & & & & & & & & & [16] \\
\hline
\end{tabular}

Of the 165 potential co-occurrences in Table 7, only twenty are attested, which is to say that the two candidate features are very close to being perfectly non-orthogonal. Viewed from the standpoint of efficiency, we note that the two-feature analysis of Kayardild TAM requires twenty-six values distributed over two features in order to cover just twenty different TAM clause types. By way of comparison, in Table 8, we show that a one-feature analysis of the system would require just sixteen values, labelled [1]-[16]. In Table 8 we assume that NONVERIDICAL is a value of POLARITY (see Appendix A.3), and we analyse the TAMA:FUTURE apprehensive complementized clauses as free variants of their semantically equivalent TAMA:EMOTIVE counterparts (see Appendix A.5). These are shown in Table 8 as [5a] [5b].

In terms of orthogonality then, the two-feature analysis of Kayardild TAM departs starkly from what we would expect from two-feature system in general. ${ }^{31}$ Consequently, in order to defend the two-feature analysis of Kayardild TAM, we will be looking for strong support from other quarters, in Sects. 5-8.

\subsection{Orthogonality of TAM and POLARITY}

In contrast to the weak orthogonality between TAM features in the two-feature analysis of Kayardild TAM, there is considerable orthogonality between POLARITY and TAM. Tables 9, 10 and 11 show the co-occurrences of the POLARITY values POSITIVE, NEGATIVE and NONVERIDICAL with TAMA (Table 9), TAMT (Table 10), and with the single-valued TAM feature (Table 11), for which we cite the numbered values from Table 8 .

\footnotetext{
${ }^{31}$ See further Bank (2014) for interesting discussion of parsimony in feature descriptions.
} 
Table 9 Co-occurrences of TAMA and POLARITY values in the two-feature TAM system

\begin{tabular}{llllllllllll}
\hline & FUNC & CONT & EMO & FUT & INS & PRIOR & ZERO & ANTE & DIR & INCIP & PREC \\
\hline POSITIVE & $\checkmark$ & $\checkmark$ & $\checkmark$ & $\checkmark$ & $\checkmark$ & $\checkmark$ & $\checkmark$ & $\checkmark$ & $\checkmark$ & $\checkmark$ & $\checkmark$ \\
NEGATIVE & & & $\checkmark$ & $\checkmark$ & $\checkmark$ & $\checkmark$ & $\checkmark$ & & & & \\
NONVERIDICAL & & & & $\checkmark$ & $\checkmark$ & $\checkmark$ & & & & & \\
\hline
\end{tabular}

Table 10 Co-occurrences of TAMT and POLARITY values in the two-feature TAM system

\begin{tabular}{lcccccccccc}
\hline & PROG & DES & HORT & POT & ACT & PAST & IMP & IMM & APPR & RES \\
\hline POSITIVE & $\checkmark$ & $\checkmark$ & $\checkmark$ & $\checkmark$ & $\checkmark$ & $\checkmark$ & $\checkmark$ & $\checkmark$ & $\checkmark$ & $\checkmark$ \\
NEGATIVE & & & $\checkmark$ & $\checkmark$ & $\checkmark$ & $\checkmark$ & $\checkmark$ & & & \\
NONVERIDICAL & & & & $\checkmark$ & $\checkmark$ & $\checkmark$ & & & \\
\hline
\end{tabular}

Table 11 Co-occurrences of POLARITY and TAM values in the one-feature TAM system

\begin{tabular}{lllllllllllllllll}
\hline & 1 & 2 & 3 & 4 & 5 & 6 & 7 & 8 & 9 & 10 & 11 & 12 & 13 & 14 & 15 & 16 \\
\hline POSITIVE & $\checkmark$ & $\checkmark$ & $\checkmark$ & $\checkmark$ & $\checkmark$ & $\checkmark$ & $\checkmark$ & $\checkmark$ & $\checkmark$ & $\checkmark$ & $\checkmark$ & $\checkmark$ & $\checkmark$ & $\checkmark$ & $\checkmark$ & $\checkmark$ \\
NEGATIVE & & & & $\checkmark$ & & $\checkmark$ & $\checkmark$ & $\checkmark$ & & $\checkmark$ & & $\checkmark$ & & & & \\
NONVERIDICAL & & & & & & & $\checkmark$ & $\checkmark$ & & $\checkmark$ & & & & & \\
\hline
\end{tabular}

Tables 9, 10 and 11 show that even though the orthogonality of NONVERIDICAL with TAM values is low, it still combines more freely with TAM values than any TAMT and TAMA values do with one another in Table 7.

\subsection{Conclusions from orthogonality}

We find that evidence from orthogonality mutually reinforces arguments from semantics (Appendix A.3), to support the conclusion that polarity and TAM in Kayardild are separate features, and of course typologically this is no surprise. At the level of specifics, NONVERIDICAL is a value of POLARITY, not TAMT, contra Round (2013). Given that, however, our examination of the orthogonality between the TAM features themselves reveals that there is little in support of a two-feature analysis of Kayardild TAM. Consequently, if we wish to maintain the two-feature analysis, we will be looking for strong support from the tests presented in the sections to follow.

\section{Semantic compositionality}

In this section we ask if Kayardild TAM exhibits semantic compositionality, as we would expect from a true, two-featured system. The question at issue is whether the meaning contributed by combinations of feature values $\{\mathbf{F}: \mathrm{A}, \mathbf{G}: \mathrm{B}\}$ is the simple combination of the meaning contributed by $\mathbf{F}$ :A and the meaning contributed by $\mathbf{G}: \mathbf{B}$. As a matter of principle, this kind of assessment is only possible where we have some 
idea of the independent meanings of F:A and G:B. We can infer such independent meanings by holding one feature value constant and varying the other. For example, if we compare across $\{\mathbf{F}: \mathrm{A}, \mathbf{G}: \mathrm{B}\},\{\mathbf{F}: \mathrm{A}, \mathbf{G}: \mathbf{C}\}$ and $\{\mathbf{F}: \mathrm{A}, \mathbf{G}: \mathrm{D}\}$, and take note of what remains semantically constant, then all else being equal, we may reasonably attribute that semantic component to F:A. This, however, requires $\mathbf{F}$ : A to co-occur with more than one value of $\mathbf{G}$. As we saw in Sect. 4, this kind of co-occurrence is absent for the majority of the feature values in the two-feature analysis of Kayardild TAM. Correspondingly, we will be constrained here to discussing those feature values which do cross-cut other feature values. For expository reasons, we begin with the POLARITY feature and then return to TAM.

\subsection{Compositionality of POLARITY vis-a-vis TAM}

Values of the POLARITY feature are almost perfectly compositional with TAM. The difference in meaning between any POLARITY:POSITIVE TAM clause and its corresponding POLARITY:NEGATIVE one is almost always solely a matter of simple negation. The one exception is that POLARITY:NEGATIVE in combination with the past tense $\mathrm{TAM}^{32}$ yields the meaning ' $\mathrm{X}$ almost happened', rather than ' $\mathrm{X}$ didn't happen', as one otherwise would expect (Evans 1995a: 261). Likewise, the NONVERIDICAL value of POLARITY, contributes a constant meaning in its combinations with TAM. ${ }^{33}$

In sum, the POSITIVE, NEGATIVE and NONVERIDICAL values of the POLARITY feature combine in a compositional manner with TAM in almost all instances, from which we conclude that there is strong evidence from compositionality, that POLARITY is a feature that is distinct from TAM (irrespective of whether TAM itself is one feature or two).

\subsection{Compositionality of the two TAM features}

Feature values in the two-feature analysis of Kayardild TAM, which co-occur with multiple other features-values are: the PROGRESSIVE, APPREHENSIVE and POTENTIAL values of TAMT, and the EMOTIVE, FUTURE, INSTANTIATED and ZERO values of TAMA. We consider these in turn.

\subsubsection{Compositionality of TAMT:PROGRESSIVE}

The feature value TAMT:PROGRESSIVE combines with TAMA:FUNCTIONAL in subordinate clauses which denote the intended function of an instrument (Round 2013: 101); and with TAMA:CONTINUOUS in main clauses to convey ongoing actions, and in subordinate clauses to convey contemporaneity with the main clause (Evans 1995a: 226, 472-474). This is summarized in Table 12.

\footnotetext{
${ }^{32}$ That is to say, with \{TAMA:PRIOR, TAMT:PAST $\}$ in the two-feature analysis.

${ }^{33}$ The difference in meaning is subtle (Evans 1995a: 374-375): the NEGATIVE treats the subject as topical and contributes a new, negated predicate (e.g. 'I didn't spear any turtle, I only speared dugong'), whereas the NONVERIDICAL takes the predicate as topical, but conveys that it is not true of the subject (e.g. 'I didn't spear the turtle, my brother speared it.').
} 
Table 12 Clausal TAM meanings involving TAMT:PROGRESSIVE

Table 13 Clausal TAM meanings involving TAMT:APPREHENSIVE

\begin{tabular}{ll}
\hline TAMA value & Clause TAM meaning \\
\hline FUNCTIONAL & $\begin{array}{l}\text { Denotes intended function of an instrument } \\
\text { Denotes ongoing, uncompleted actions; or } \\
\text { contemporaneity in subordinate clauses }\end{array}$ \\
\hline
\end{tabular}

TAMA value Clause TAM meaning

\begin{tabular}{ll}
\hline EMOTIVE & Undesirable eventualities, to be avoided \\
FUTURE & Undesirable eventualities, to be avoided \\
\hline
\end{tabular}

It is difficult to pinpoint any semantic constant across the two TAM types in Table 12, which one might attribute specifically to TAMT:PROGRESSIVE. Moreover, the TAMA values with which TAMT:PROGRESSIVE co-occurs, themselves co-occur with no other value of TAMT, and hence there is nothing to prevent us attributing the entire TAM meanings of these clause type to the TAMA values, while claiming that TAMT:PROGRESSIVE is semantically empty. In sum, there is little to work with here, and what little we can deduce provides no evidence that the PROGRESSIVE value of TAMT combines compositionally with TAMA.

\subsubsection{Compositionality of TAMT:APPREHENSIVE}

As is discussed in Appendix A.5, TAMT:APPREHENSIVE combines solely with TAMA:EMOTIVE in uncomplementized clauses. In complementized clauses, it combines with both TAMA:EMOTIVE and TAMA:FUTURE with no discernable difference in meaning, at least within our corpus. Thus, there is no positive evidence that TAMT:APPREHENSIVE combines in a compositional manner with TAMA (Table 13).

\subsubsection{Compositionality of TAMT:POTENTIAL}

The feature value TAMT:POTENTIAL combines with TAMA:FUTURE to convey a wide range of potential-like TAM meanings, such as futurity, expectation, prescription, desire, possibility as well as marking purposives and clausal complements of communication verbs (Evans 1995a: 258-260, 518-520). As we show in Appendix A.6, it combines with TAMA:INSTANTIATED in non-future counterfactual clauses.

In this instance, a strong case can be made for TAMT:POTENTIAL possessing a constant meaning, which we might describe informally as 'non-actuality'. The next question is, whether the total meanings contributed by \{TAMT:POTENTIAL, TAMA:FUTURE \} and \{TAMT:POTENTIAL, TAMA:INSTATIATED $\}$ can be viewed as the simple addition, of the 'non-actuality' meaning of TAMT:POTENTIAL, to the meanings of TAMA:FUTURE and TAMA:INSTANTIATED. In order to derive precisely the set of meanings in Table 14, we would need to attribute to TAMA:FUTURE a complex set of meanings related most likely through a network of family resemblances; and to TAMA:INSTANTIATED something like 'non-futurity'. This is diffi- 
Table 14 Clausal TAM meanings involving TAMT:POTENTIAL

Table 15 Clausal TAM meanings involving TAMA:EMOTIVE

\begin{tabular}{ll}
\hline TAMA value & Clause TAM meaning \\
\hline FUTURE & $\begin{array}{l}\text { Futurity, expectation, prescription, desire, } \\
\text { possibility; purposives; clausal complements } \\
\text { of communication verbs } \\
\text { Non-future counterfactuals }\end{array}$ \\
\hline
\end{tabular}

\begin{tabular}{ll}
\hline TAMT value & Clause TAM meaning \\
\hline DESIDERATIVE & $\begin{array}{l}\text { Desirable eventualities; conditional protases } \\
\text { for hypothetical future events; clausal } \\
\text { complements of indirect communication } \\
\text { verbs }\end{array}$ \\
HORTATIVE & $\begin{array}{l}\text { Immediately relevant, desirable eventualities } \\
\text { APPREHENSIVE }\end{array}$ \\
\hline
\end{tabular}

cult to put into practice for TAMA:FUTURE without entertaining further complications which would take us away from simple compositionality-recall that when TAMA:FUTURE combines with TAMT:APPREHENSIVE it appears to contribute no distinct meaning at all. For TAMA:INSTANTIATED, however, we are arguably near to compositionality. The INSTANTIATED value of TAMA is associated with non-futurity (cf Appendix A.4). The only complication would be to ensure that the 'non-actuality' of TAMT:POTENTIAL and 'non-futurity' of TAMA:INSTANTIATED sum solely to 'counterfactuality', and not, for example to 'non-future expectation' and 'non-future ability'. Ascertaining the precise feasibility of this is beyond the scope of our present study, however we can conclude that the semantics of \{ TAMT:POTENTIAL, TAMA:INSTANTIATED $\}$ is reasonably compositional, perhaps at the same level as when POLARITY:NEGATIVE combines with past tense TAM to yield a meaning of 'almost' (Sect. 5.1). On the other hand, the semantics of \{ TAMT:POTENTIAL, TAMA:FUTURE \} is not compositional.

\subsubsection{Compositionality of TAMA:EMOTIVE, FUTURE and ZERO}

TAMA:EMOTIVE combines with the TAMT values DESIDERATIVE, HORTATIVE and APPREHENSIVE, to yield the meanings summarized in Table 15 (Evans 1995a: 26265). A common thread appears to be 'desire', 34 however, TAMT:DESIDERATIVE and TAMT:HORTATIVE only co-occur with TAMA:EMOTIVE, and thus one could argue that the full semantic value listed in Table 15 comes from the TAMT values, not TAMA:EMOTIVE. Likewise, apprehensive clauses show no discernable semantic difference when TAMA:EMOTIVE is substituted with TAMA:FUTURE, again suggesting that it is TAMA that supplies the full meaning. In sum, there is little evidence that TAMA:EMOTIVE combines compositionally with TAMT values.

\footnotetext{
${ }^{34}$ Evans (1995a: 402) describes these as 'emotive' propositions (without characterizing them in greater detail), and also notes an alternative, along the lines proposed here, that the EMOTIVE denotes 'situations which it is the "goal" or "purpose" of the speaker to bring about or prevent" (1995a: 411).
} 
Table 16 Clausal TAM meanings involving TAMA:FUTURE

\begin{tabular}{ll}
\hline TAMT value & Clause TAM meaning \\
\hline POTENTIAL & $\begin{array}{l}\text { Futurity, expectation, prescription, desire, } \\
\text { possibility; purposives; clausal complements } \\
\text { of communication verbs }\end{array}$ \\
APPREHENSIVE & Undesirable eventualities, to be avoided \\
\hline
\end{tabular}

Table 17 Clausal TAM meanings involving TAMA:ZERO

\begin{tabular}{ll}
\hline TAMT value & Clause TAM meaning \\
\hline RESULTATIVE & $\begin{array}{l}\text { Completed events with a lasting effect } \\
\text { (with active verbs yields passive diathesis) } \\
\text { IMPERATIVE }\end{array}$ \\
\hline
\end{tabular}

TAMA:FUTURE combines with TAMT:APPREHENSIVE, where it appears to make no meaningful contribution, and with TAMT:POTENTIAL where it would appear not to contribute anything to the 'non-actuality' meaning discussed above in Sect. 5.2.3 (Table 16).

TAMA:ZERO combines as shown in Table 17 with TAMT:RESUlTATIVE and TAMT:IMPERATIVE, both of which co-occur with no other TAMA value. There is no evidence for compositionality here.

\subsection{Conclusions from compositionality}

The POLARITY feature and its values combine with TAM in a compositional manner, the one exception being the less than fully compositional combination of POLARITY:NEGATIVE and past tense TAM to yield an 'almost' meaning. In contrast, the two putative TAM features never combine in a fully compositional fashion. In most instances, compositionality cannot be assessed, since values of one feature do not combine with more than one value of the other feature. In cases when one value does combine with multiple others, we typically found that the single value appeared to contribute no meaning, with the entire semantics coming from its various partners. The one instance which came close to compositionality was the combination of TAMT:POTENTIAL 'non-actuality' with TAMA:INSTANTIATED 'non-future' to yield 'non-future counterfactual'. As we observed, this most-compositional instance of TAM semantics was approximately on par with the least-composition combination of POLARITY and TAM.

This is not the semantic behaviour that one expects from a true, two-feature system. By way of contrast, if we assume that Kayardild has a one-feature TAM system, then the semantic content of that single feature's values will typically be identical to the meaning of just one feature value in the pair which it replaces, and namely, the feature value in that pair which combines with only one partner. For example, the value designated as [1] in Table 8 replaces the two-feature combination of \{TAMT:PROGRESSIVE, TAMA:FUNCTIONAL\}; TAMA:FUNCTIONAL has no other partner TAMT value, and the semantics of feature value [1] would be identical to the semantics we found ourselves attributing to TAMA:FUNCTIONAL in Sect. 5.2.1. The overarching pattern is this: the meaning of TAM features in the two-feature system 
Table 18 Feature values and the clause structures in which they appear

\begin{tabular}{|c|c|c|c|}
\hline \multirow{2}{*}{$\begin{array}{l}\text { Clause } \\
\text { type }\end{array}$} & \multicolumn{2}{|l|}{ Two-feature system } & \multirow{2}{*}{$\frac{\text { One-feature system }}{\text { TAM }}$} \\
\hline & TAMT & TAMA & \\
\hline $\mathrm{u}$ & IMMEDIATE, IMPERATIVE, & ZERO*, INSTANTIATED* & [9] [12] \\
\hline $\mathrm{u}, \mathrm{c}$ & $\begin{array}{l}\text { ACTUAL, APPREHENSIVE, } \\
\text { DESIDERATIVE, } \\
\text { HORTATIVE, PAST, } \\
\text { POTENTIAL, } \\
\text { PRECONDITION }\end{array}$ & $\begin{array}{l}\text { EMOTIVE, FUTURE*, } \\
\text { INSTANTIATED*, } \\
\text { PRECONDITION, PRIOR }\end{array}$ & $\begin{array}{l}{[3][4][5][6][7][8]} \\
{[10][13]}\end{array}$ \\
\hline $\mathrm{u}, \mathrm{c}, \mathrm{e}$ & ANTECEDENT & ANTECEDENT & [14] \\
\hline $\mathrm{c}$ & & FUTURE* & $([5 b])$ \\
\hline $\mathrm{u}, \mathrm{e}$ & $\begin{array}{l}\text { DIRECTED, } \\
\text { PROGRESSIVE*, } \\
\text { RESULTATIVE }\end{array}$ & $\begin{array}{l}\text { CONTINUOUS, DIRECTED, } \\
\text { ZERO* }^{*}\end{array}$ & {$[2][11][15]$} \\
\hline $\mathrm{e}$ & INCIPIENT, PROGRESSIVE** & FUNCTIONAL, INCIPIENT & [1] [16] \\
\hline
\end{tabular}

Notes: (i) the information displayed in Table 18 takes into account refinements summarized in Sect. 3.8 and therefore differs marginally from the initial lists (20) and (21) in Sect. 3.4

(ii) values of TAMT and TAMA are asterisked if their distribution is dependent on which particular partner feature value they are paired with

(iii) values of the single feature TAM are cited in terms of the numbers in Table 8

appears overwhelmingly to reside in feature values which participate in just one feature combination, while those features that combine with multiple partners are semantically vacuous. This is the antithesis of compositionality. We conclude, therefore, that the semantic evidence weighs against Kayardild TAM being a two-feature system, and instead points clearly to a single-feature system.

\section{Licensing in different clause structures}

In Sects. 4-5 we considered the two putative TAM features of Kayardild with respect to one another. However, the logic of justifying a feature system extends also to that system's interaction with other components of the grammar. For example, in Russian, the distinctness of NUMBER and CASE is reflected in the fact the verbs may agree for NUMBER but not CASE, and that verbs and prepositions may govern CASE but not NUMBER. In Sects. 6-7 we examine the interaction of TAM with other parts of the grammar of Kayardild. In this section we return to the differential permissibility of TAM types among the three clause structures of Kayardild introduced in Sect. 3.4: uncomplementized full clauses (u-clauses), complementized full clauses (c-clauses), and embedded VPs (e-clauses). We ask whether generalizations about TAM types and their distribution across clause structures, are more simply stated within a system of two TAM features or of one.

Table 18 shows these clause structure(s), and the feature values which are compatible with them, for the features TAMT and TAMA in the two-feature system, and the single feature TAM in the one-feature system.

In both systems, it is most efficient to begin with a statement that by default, a TAM feature value is compatible with u-clauses and c-clauses; after that only the 
exceptions need to be listed. In the one-feature system, there are eight such exceptional feature values whose clause compatibility will need to be stated. In addition, realization rules (cf. Sect. 8 below) will need to state that for value [5], the realization variant [5b] is available only in c-clauses. In total then, the one-feature system requires one default statement, eight statements about exceptions, and one realization rule that refers to clause structure.

In the two-feature system, there are fifteen feature values for which 'exception' statements need to be made, and moreover, there are four whose clause compatibility can only be fully stated with reference to the other feature value with which it is paired: for each of those feature values, two of these more complex exception statements are needed. In total then, the two-feature system requires one default statement, eleven simple exception statements, and eight complex exception statements.

Comparing the two analyses, we can first observe that neither permits us to make particularly succinct statements about how TAM relates to clause structures, rather the system is characterized by considerable idiosyncrasy. Compared to the twofeature analysis, the one-feature analysis requires only half as many statements to be made in order describe which feature values are compatible with which clause structures. This may seem unsurprising, given that the one-feature analysis makes use of only about half as many feature values; but it suggests that the additional values in the two-feature analysis contribute rather little. We conclude that in terms of the interaction between TAM and clause structure, the one-feature analysis is more efficient than the two-feature analysis.

\section{Distribution across constituents of the clause}

Kayardild TAM also interacts with syntax in terms of the distribution, across DPs in the clause, of TAM inflection on athematic stems. As discussed in Sect. 3.3, in uncomplementized full clauses, TAM inflection can appear on all athematic stems of words under either $\mathrm{VP}_{\beta}, \mathrm{VP}_{\gamma}$ or $\mathrm{VP}_{\delta}$, depending on the specific TAM type. By default, TAM types associate with $\mathrm{VP}_{\gamma} \cdot{ }^{35}$ Just one type associates with $\mathrm{VP}_{\delta}$, namely TAMA:CONTINUOUS in the two-feature analysis, or TAM:2 in the one-feature analysis; this exception is expressed with equal succinctness in both analyses. Three TAM types associate with $\mathrm{VP}_{\beta}$. These are TAM:8, TAM:9 and TAM:15 in the one-feature analysis, requiring three statements to be made. In the two-feature analysis they are TAMA:INSTANTIATED (paired with TAMT:ACTUAL or with TAMT:IMMEDIATE), and TAMA:DIRECTED; this requires just two statements, namely that TAMA:INSTANTIATED and DIRECTED associate with $\mathrm{VP}_{\beta}$. In this sense, the two-feature analysis is marginally more efficient.

Let us take stock of the arguments for and against the two-feature account. In terms of orthogonality (Sect. 4), the one-feature analysis is overwhelmingly favoured. The compositionality test (Sect. 5) similarly points strongly to one feature. For licensing (Sect. 6) the one-feature account is clearly the more efficient. However, in terms of

\footnotetext{
${ }^{35}$ Round (2013: 114) notes that for some TAM types the available data underdetermines which node precisely they associate with. In all those instances, the available data is consistent with the default, $\mathrm{VP}_{\gamma}$.
} 
Table 19 Morphomic realizations of TAM (one-feature analysis); also indicating syncretism across values, on thematic and athematic stems, and approximate semantic value

\begin{tabular}{rlll}
\hline TAM & On thematic stems & On athematic stems & TAM semantics \\
\hline 1 & $\mu \mathrm{N}$ & $\mu \mathrm{UTIL}$ & Function of an instrument \\
2 & $\mu \mathrm{N}$ & $\mu \mathrm{OBL}$ & Continuing \\
3 & $\mu \mathrm{DES}$ & $\mu \mathrm{OBL}$ & Desiderative \\
4 & $\mu \mathrm{OBL}$ & $\mu \mathrm{OBL}$ & Hortative \\
5 & $\mu \mathrm{APPR}$ & $\mu \mathrm{OBL}(\mathrm{u}), \mu \mathrm{OBL} \sim \mu$ PROP $(\mathrm{c})$ & Apprehensive \\
6 & $\mu$ PROP & $\mu$ PROP & Potential \\
7 & $\mu$ PROP & $\mu \mathrm{LOC}$ & Counterfactual \\
8 & $\varnothing(\mathrm{c}), \mu \mathrm{LOC}(\mathrm{u})$ & $\mu \mathrm{LOC}$ & Non-future \\
9 & $\mu \mathrm{LOC}$ & $\mu \mathrm{LOC}$ & Immediate present \\
10 & $+\mu$ CONS & $\mu \mathrm{LOC}-\mu$ ABL & Past \\
11 & $\varnothing$ & $\mu \mathrm{RES}$ & Resultative \\
12 & $\varnothing$ & $\varnothing$ & Imperative \\
13 & $\mu \mathrm{N}-\mu \mathrm{CONS}$ & $\mu \mathrm{CONS}$ & Antecedent \\
14 & $\mu \mathrm{LOC}-\mu \mathrm{ALL}$ & $\mu \mathrm{LOC}-\mu \mathrm{ALL}$ & Spatially extended event; Purpose of motion \\
15 & $\mu \mathrm{N}-\mu \mathrm{DAT}-\mu \mathrm{MID}-\mathrm{J}$ & $\mu \mathrm{DAT}-\mu \mathrm{MID}-\mathrm{J}$ & Incipient \\
16 & $+\mu \mathrm{CONS}$ & $\mu \mathrm{LOC}-\mu \mathrm{ABL}$ & Precondition \\
\hline
\end{tabular}

distribution (Sect. 7) we at last find some (weak) evidence which favours a twofeature analysis. With this in mind, we turn to matters of exponence.

\section{Exponence}

Canonically, a feature value would be realized uniformly by just one, overt exponent in all contexts, and that exponent would be distinct from all others in the system. Real systems often depart from this canonical ideal, and the degree to which the system is canonical depends, of course, on one's analysis of the underlying features and values. In this section we assess the two analyses of Kayardild TAM in terms of the canonicity of their patterns of exponence. It will be recalled from Sect. 3.3 that in Kayardild, morphosyntactic features are realized as morphomic elements, and so it is in terms of these morphomic elements that we discuss the topic of exponence below.

\subsection{Syncretism under the two analyses}

Table 19 shows the morphomic exponents of the sixteen values of TAM, the single TAM feature of the one-feature analysis. The TAM feature receives overt exponence both on thematic stems and athematic stems, as shown. In some instances the exact exponence varies according to clause type, indicated as (c) for complementized and (u) uncomplementized, and in one instance (for TAM:5 as realized on athematic stems in complementized clauses) there are two exponents in variation.

Many of the exponents in Table 19 are shared. For example, TAM:1 and TAM:2 share their exponents on thematic stems. So too do TAM:6 and TAM:7, and TAM:11 and TAM:12. Likewise, on athematic stems there are identical exponents for TAM:2, 
Table 20 Feature values' morphomic realizations (two-feature analysis)

\begin{tabular}{llll}
\hline TAMT & On thematic stems & TAMA & On athematic stems \\
\hline ACTUAL & $\varnothing(\mathrm{u}), \mu \mathrm{LOC}(\mathrm{c})$ & ANTECEDENT & $-\mu \mathrm{CONS}$ \\
ANTECEDENT & $\mu \mathrm{N}-\mu \mathrm{CONS}$ & CONTINUOUS & $\mu \mathrm{OBL}$ \\
APPREHENSIVE & $\mu \mathrm{APPR}$ & EMOTIVE & $\mu \mathrm{OBL}$ \\
DESIDERATIVE & $\mu \mathrm{DES}$ & DIRECTED & $\mu \mathrm{LOC}-\mu \mathrm{ALL}$ \\
DIRECTED & $\mu \mathrm{LOC}-\mu \mathrm{ALL}$ & FUNCTIONAL & $\mu \mathrm{UTIL}$ \\
HORTATIVE & $\mu \mathrm{OBL}$ & FUTURE & $\mu$ PROP \\
IMMEDIATE & $\mu \mathrm{LOC}$ & INCIPIENT & $\mu \mathrm{DAT}-\mu \mathrm{MID}-\mathrm{J}$ \\
IMPERATIVE & $\varnothing$ & INSTANTIATED & $\mu \mathrm{LOC}$ \\
INCIPIENT & $\mu \mathrm{N}-\mu \mathrm{DAT}-\mu \mathrm{MID}-\mathrm{J}$ & PRECONDITION & $\mu \mathrm{LOC}-\mu \mathrm{ABL}$ \\
PAST & $+\mu$ CONS & PRIOR & $\mu \mathrm{LOC}-\mu$ ABL \\
POTENTIAL & $\mu$ PROP & ZERO & $\emptyset$ \\
PRECONDITION & $+\mu \mathrm{CONS}$ & & \\
PROGRESSIVE & $\mu \mathrm{N}$ & & \\
RESULTATIVE & $\mu \mathrm{RES}$ & & \\
\hline
\end{tabular}

ТАМ:3 and ТАМ:4, and for ТАМ:7, ТАМ:8 and ТАМ:9. In the canonical situation, this kind of syncretism would not happen; each feature value would have its own, distinct exponent, which would not vary across stems.

Morphomic exponents in the two-feature system are shown in Table 20. In this system there is just one instance of syncretism between values of the same feature, namely TAMA:CONTINUOUS and TAMA:EMOTIVE. It is important, therefore, to ask how the two-feature system avoids syncretism.

Effectively, the two-feature analysis avoids syncretism among the values of its features, by taking as the basis of those values the very syncretisms that characterize the one-feature analysis. For example, in the one-feature analysis, TAM:1 and TAM:2 (following the labels of Table 8) share their syncretic, $\mu \mathrm{N}$ exponent on thematic stems, and in the two-feature analysis, TAM: 1 and TAM:2 correspond to TAMT:PROGRESSIVE. Likewise, in the one-feature analysis, TAM:7, TAM:8 and TAM:9 share their $\mu$ LOC exponent on athematic stems, and in the two-feature analysis, TAM:7, TAM:8 and TAM:9 correspond to TAMA:INSTANTIATED. If we consider this property of the two-feature analysis in light of findings in Sects. 4-7, we see that the feature values of the two-feature analysis are based not on orthogonality, or semantics, or on interactions with syntax, but on patterns of exponence. What unifies TAMT:PROGRESSIVE, for example, is simply that it is realized as $\mu \mathrm{N}$. Consequently, while the single TAM feature often has multiple values mapping syncretically onto one and the same exponent, the two features TAMA and TAMT typically have a one-to-one mapping between their values and their exponents. All else being equal, this directness of mapping might count in favour of the two-feature analysis, on the grounds of simplicity, for example. However, it is important to ask: is this still true, within the context of our overarching analysis of Kayardild morphology? We answer that question in Sect. 8.2, and in Sect. 8.3 we draw parallels between Kayardild TAM and the discussion in Sect. 2.2 of 'split ergativity'. 


\subsection{Discordance with the logic of morphomic analysis}

In Sect. 3 we saw that there are strong grounds for analysing Kayardild morphological exponence in morphomic terms. The core reason is that by doing so we make possible an elegant and balanced analysis of the abundance of instances where multiple inflectional feature values, throughout the inflectional system, map onto the same morphomic exponent. Worryingly though, the basis of the two-feature analysis of Kayardild TAM runs in the opposite direction: it reduces the amount of many-to-one mappings by packaging the 'many' into single feature values. In that sense, the basis of the two-feature analysis runs counter to the overarching analysis of Kayardild, as it attempts to package shared exponence within feature values, rather than in the mappings between feature values and morphomic categories. The one-feature analysis is more in keeping with the general analysis of the morphological system.

\subsection{One feature masquerading as two}

The reader may have noticed some similarities between Table 19, which shows syncretism in the one-feature analysis of Kayardild TAM, and Table 3, which showed syncretism in the one-feature analysis of Guugu Yimidhirr CASE. The parallels are strong. In both instances, the two-feature analysis was the first to be proposed by linguists; it was inspired by patterns of exponence, in particular by patterns of syncretism across values which differ between two kinds of stem (pronouns versus nouns in Guugu Yimidhirr, and thematic versus athematic stems in Kayardild); and it turns out to be largely at odds with evidence gained from other aspects of the inflectional system. In Sect. 2.2 we also noted that the two-feature analysis of Guugu Yimidhirr CASE placed a particular demand on the morpho-syntactic system, requiring a verb either to 'peek' ahead to look at the word class of its dependent before assigning the correct case feature and value, or to assign two feature specifications (both CASEP and CASEN), although only one feature would be realized on any given word. The latter analysis, in which two features are assigned but only one is realized, is in fact entirely parallel to Round's (2013) formal analysis of TAMA and TAMT. Both TAMA and TAMT are assigned to words under the appropriate VP node, but only one of them is realized on a given word. Without rehearsing the details of Round's formal analysis (see Round 2013: 169-176), we simply note that by adopting a single-feature analysis of TAM, the morphological system of Kayardild no longer needs to stipulate this complementarity between the realization of TAMA and TAMT, and it no longer needs to associate a large number of words in every clause with two TAM features, of which only one is ever visible. The formal system thereby becomes both simpler and more transparent under a single-feature analysis.

\section{Conclusions}

\subsection{For the formal analysis of Kayardild morphology}

We have argued for an analysis of Kayardild, according to which there is just one TAM feature. That feature, which we name simply TAM, has sixteen values whose 
Table 21 Sixteen values of the single TAM feature and their equivalents

\begin{tabular}{|c|c|c|c|c|c|}
\hline & \multirow[t]{2}{*}{ TAM value } & \multicolumn{2}{|c|}{ Evans (1995a) } & \multicolumn{2}{|c|}{ Round (2013) } \\
\hline & & TAMV & MODAL CASE & TAMT & TAMA \\
\hline 1 & FUNCTIONAL & - & - & CONT & FUNC \\
\hline 2 & CONTINUOUS & $-^{\mathrm{a}}$ & $-\mathrm{b}$ & CONT & PROG \\
\hline 3 & DESIDERATIVE & DES & MOBL & DES & EMO \\
\hline 4 & HORTATIVE & HORT & MOBL & HORT & EMO \\
\hline 5 & APPREHENSIVE & APPR & MOBL, MPROP & APPR & EMO, FUT \\
\hline 6 & Potential & РОТ & MPROP & POT & FUT \\
\hline 7 & COUNTERFACTUAL & РОТ & MLOC & POT & INS \\
\hline 8 & ACTUAL & ACT, IMM & MLOC & ACT, PRES & INS \\
\hline 9 & IMMEDIATE & IMM & MLOC & IMM & INS \\
\hline 10 & PAST & PAST & MABL & PAST & PRIOR \\
\hline 11 & RESUltative & RES & ZERO & RES & ZERO \\
\hline 12 & IMPERATIVE & IMP & ZERO & IMP & ZERO \\
\hline 13 & ANTECEDENT & $-^{\mathrm{c}}$ & ${ }^{\mathrm{d}}$ & ANTE & ANTE \\
\hline 14 & DIRECTED & DIR & MALL & DIR & DIR \\
\hline 15 & INCIPIENT & - & - & INCIP & INCIP \\
\hline 16 & PRECONDITION & PREC & MABL & PREC & PREC \\
\hline
\end{tabular}

anflectional nominalization

b OBLIQUE ASSOCIATING CASE

${ }^{\mathrm{c}}$ Inflectional nominalization, plus CONSEQUENTIAL CASE

$\mathrm{d}_{\text {CONSEQUENTIAL RELATIONAL CASE }}$

semantic value and morphomic exponents were listed in Table 19. In Table 21, we propose a set of labels for each value of TAM and present a comparison with equivalents in the analyses of Evans (1995a) and Round (2013).

In terms of Round's (2013) formal analysis of the morphology-syntax interface in Kayardild, our revision is easily integrated into the broader analysis, and has a simplifying effect. We can state this briefly. Our TAM values will need to attach in the syntax at the same nodes to which Round's equivalent TAMA feature attaches; this will ensure that features percolate to the requisite DP constituents. Round's analysis of competition between the realization of TAMA and TAMT becomes redundant once these are replaced by a single feature TAM, for which one need only formulate rules of stem-sensitive allomorphy in accordance with the facts in Table 19. As we argued in Sect. 8.2, our revision is also more in keeping with the overarching, morphomic analysis of the morphological system. We also argued that Round's (2013) NONVERIDICAL value of TAMT is better analysed as a value of the POLARITY feature, which we can label NEGATIVE2.

\subsection{For the typology of feature systems}

There is a view, held by many but certainly not all linguists, that there is a fixed list of features, from which individual languages employ some subset, see for instance, 
Zwicky (1986: 988) and Chomsky (2001: 10). This is a view we share (as in Corbett 2012: 107-111), though this does not impact directly on our analysis of Kayardild. Related to this view is another, directly relevant to our analysis, which we shall call the "No Concurrent Features Conjecture". According to this view, a language may have, or not have, each of the possible features, but it may not have two instances of the same feature. In other words, a language may have a CASE system, or not have one, but it may not have two CASE systems. The conjecture is not generally stated directly, but we see it in linguists' use of terms: where a language might be analysed as contravening the conjecture, we may find terms chosen to avoid the issue. Thus languages which arguably have two gender systems may be described as having a gender system and a classifier system.

In our view, the conjecture is an excellent rule of thumb. Following Ockham, we should not propose two features of the same type if there is an adequate analysis with just one. But we stress that we do not rule out such analyses. As just one example, consider gender in Michif. This language was formed in Canada through the marriages of local women who spoke Cree and men (fur traders) who spoke French. It combines an animate-inanimate gender system of the type we expect to find in an Algonquian language with a masculine-feminine gender system. These two systems occur together in the noun phrase. Research on this language is reported in Bakker and Papen (1997) and Bakker (1997). The data specific to gender are available in Corbett (2006: 269-270), while Corbett (2012: 176) discusses the Michif situation as an instance of a combined gender system. Thus Michif could be argued to have two gender features, that is, two orthogonal features, each of which independently would qualify as a gender feature. ${ }^{36}$ Thus we do not rule out the possibility that a language should have two features of the same type. If it does, that is unusual, interesting and worthy of further study. In our Michif example, there are special circumstances which gave rise to the two potential gender systems but the result, we suggest, has two concurrent gender systems.

Given that we would take a critical view of analyses with concurrent features, but certainly not rule them out, we have re-examined the evidence in Kayardild and have concluded, unlike the previous accounts, that Kayardild has one TAM feature. Just as Goddard (1982) demonstrated that a single case feature offered a more insightful analysis of systems previously analysed as showing split ergativity so, we suggest, our comparable analysis of Kayardild is a step forward compared with the earlier accounts. ${ }^{37}$ This means that we have removed a potentially strong candidate for concurrent TAM systems. On the way, we had to return to the data and sharpen the analysis of Kayardild at key points. We are thus making a methodological point: taking the

\footnotetext{
${ }^{36}$ See Corbett and Fedden (2015) for extended discussion of potentially concurrent gender and classifier systems. Members of the Set-theoretical School grappled with the problem of gender and animacy in various Slavonic languages, as described with great care and insight by van Helden (1993), but their concerns were rather different. Van Helden himself considers briefly the question of a language with two gender-like categories, though he was not aware of any such language (1993: 905).

${ }^{37}$ The issues are far from obvious: thus Evans and Round were strong promoters of Goddard's insights into CASE, but found sufficient evidence in Kayardild to propose concurrent TAM analyses. Again we do not rule out the possibility of a language having two CASE systems: see the interesting analysis of Ossetic using concurrent case systems in Belyaev (2014).
} 
issue of concurrent versus single features seriously has led us to a better analysis. ${ }^{38}$ And we are also making a claim about competence: we do not need to propose the more complex system as part of the competence of speakers of Kayardild.

Though we have removed Kayardild from the list of potential examples of concurrent feature systems, we have not ruled out such systems. Nor indeed do we deny the existence of less clear, in-between systems. These would be expected, if languages can move to and from having concurrent systems.

\subsection{Rewards of reanalysis}

The Kayardild language, at the height of its power and world influence (as Evans 1995 c nicely put it) had perhaps 120 speakers. While the number of speakers has declined, the impact of Kayardild on the field of linguistics has been considerable, primarily as a result of Evans' grammar (1995a). Any linguist who thinks they have a clear notion of what is a "possible human language" might well check it against that grammar, to have their notion refined or perhaps shaken. The influence of Kayardild continues, for instance through Round (2013, 2015, 2016).

We have revisited one of the areas where Kayardild is particularly interesting, and one where Evans and Round proposed relatively similar analyses. In slightly different ways, both claimed that there were two TAM features in Kayardild. Among all the other unusual traits of Kayardild this one had not drawn particular attention: however, while it is perfectly possible for a language to have two features of the same type, this is relatively unusual. In the current paper we have given a reanalysis of TAM in Kayardild which is cross-linguistically more usual. We have treated it in a way that fits more readily within the typology of feature systems. In doing so, we had to look carefully at the arguments which would justify postulating two features rather than one, and this constitutes our contribution to the more general typology of feature systems. These arguments led us to revisit the corpus of Kayardild, to check on the instances which are rare or in some cases questionable, and to give a more refined analysis of the data.

We have moved from the fascination of an interesting corner of the grammar of Kayardild, to the typology of features, and back to the corpus of Kayardild. As a result, we found Kayardild to be both exotic and ordinary.

Acknowledgements At various times this research was funded by: the Arts and Humanities Research Council, UK (grant Combining Gender and Classifiers in Natural Language), the Australian Research Council (grant DE150101024 and the Australian Research Council Centre of Excellence for the Dynamics of Language), and the European Research Council (grant ERC-2008-AdG-230268 MORPHOLOGY). This support is gratefully acknowledged. A version of this paper was given at the Linguistics Association of Great Britain, University College London, 15-18 September 2015; we thank those present for useful discussion. We are also grateful to Penny Everson for her help in preparing the manuscript. Finally, we are thankful to two anonymous referees and to the Editors for their careful reading and helpful suggestions.

${ }^{38}$ The account we have given for recognizing features, and hence the possibility of concurrent systems, relates directly to work in Canonical Typology (see the criteria for canonical features and values discussed in Corbett 2012: 156-163). In essence we have clarified and extended proposals sketched there. 
Open Access This article is distributed under the terms of the Creative Commons Attribution 4.0 International License (http://creativecommons.org/licenses/by/4.0/), which permits unrestricted use, distribution, and reproduction in any medium, provided you give appropriate credit to the original author(s) and the source, provide a link to the Creative Commons license, and indicate if changes were made.

\section{Appendix: Corpus study}

This section contains detailed evidence on key empirical points bearing directly on the question of whether we analyse Kayardild as having one TAM feature or two. Rehearsing this evidence is essential for setting our argument on a firm footing. The essential points are: in Appendix A.2 the removal of Round's TAMA:NEGATORY value from the inventory of athematic TAM values, on the grounds of evidence from the interface between syntax and inflection; in Appendix A.3 the identification of a feasible reanalysis of NONVERIDCAL as a value of POLARITY rather than TAMT; in Appendix A.4 the simplification of Round's three-way distinction in present tense TAM types to a two-way distinction, after considering evidence from usage and frequency; in Appendix A.5 the simplification of Kayardild's range of apprehensive clause types, from three to two, after identifying more parsimonious alternative analyses; and in Appendix A.6 the identification of a consistently counterfactual usage of the combination of TAMA:INSTANTIATED and TAMT:POTENTIAL. We begin by introducing the corpus in Appendix A.1.

\section{A.1 The corpus}

The corpus comprises on the order of 12,000 distinct ${ }^{39}$ multiword utterances in Kayardild, sourced from recordings by Stephen Wurm in 1960; Normal B. Tindale in 1960 and 1963; Nick Evans from 1984 to the present; and Erich Round from 2005 to 2007; as well as printed examples in Evans (1995a, 1995b, 2003) and Round (2009, 2013). All transcriptions were by Erich Round, produced between 2005 and the present. The recordings by Wurm, which supply many of the example sentences in Evans (1995a), were transcribed in full. Other recording sets were transcribed in part. Searches of transcriptions were conducted within the software application ELAN (Wittenburg et al. 2006), using regular expression search strings followed up with manual investigation of search results. For printed sources, full-text searches were conducted using literal strings.

Our object of study is the traditional, or classical, Kayardild language, spoken by speakers who were fluent at the time when they left Bentinck Island in the late 1940s, and who maintained that fluency through their lifetimes. This was the variety studied by Evans (1995a) and Round (2013). With this in mind, we were careful to ensure that examples in our corpus should be representative of that variety and not any other, as both Round (2013: 3) and Evans (1995a: 54-56, 65, 149, 406, 517) note that younger speakers' Kayardild can differ morphologically from the classical variety. Wurm and Tindale recorded only the variety of Kayardild that we wish to focus on, and in Round's and Evans' recordings, speakers of that variety can be reliably

\footnotetext{
${ }^{39}$ That is, the same content uttered on multiple occasions is counted only once.
} 
identified. However, in the case of written examples for which we have not found a corresponding recording, our approach was to exercise caution. The experience of the first author is that even speakers of classical Kayardild will at times accept suggested, ungrammatical sentences of Kayardild as grammatical, and speakers of non-classical varieties may do the same when asked to judge putative sentences of the classical language. For this reason, we place a low level of certainty on the representativeness, with respect to classical Kayardild, of sentences which are obviously constructed by linguists, such as those in Evans (2003) which illustrate TAM possibilities by the presentation of a paradigm-like set of minimally varying sentences; and sentences which are possibly constructed by linguists, such as some few sentences from Evans (1995a) which vary minimally from attested, recorded sentences by Wurm. That being said, such examples were few in number, and we will mention them only infrequently in the remainder of the appendix.

\section{A.2 Syntactic evidence against TAMA:NEGATORY}

In this section we present syntactic evidence which makes Round's (2013) postulation of a NEGATORY value of TAMA untenable. The corpus reveals examples in which the distribution across the clause of the relevant marker /-wari/ is inconsistent with it being a realization of a TAMA value. Instead, the distribution of /-wari/ is consistent with Evans' (1995a) analysis, that /-wari/ marks CASE:PRIVATIVE. We refine this slightly: the surface forms at issue are markers of both CASE:PRIVATIVE and TAM, namely TAMA:INSTANTIATED.

In examples (27)-(30) of Sect. 3.5, we saw that Kayardild possesses a set of semantically negative clauses in which the marker -n-marri appears on all thematic stems of the sentence. In such sentences, DPs within the VP have been attested with inflections for TAMA:INSTANTIATED (28), TAMA:FUTURE (29) and TAMA:PRIOR (30). They have also been attested with a marker which is underlyingly /-wari/, for which there are two analyses with prima facie plausibility. The first analysis, adopted by Evans (1995a: 475) is that /-wari/ is a realization of CASE:PRIVATIVE as shown in the glossing of dangkawalanymarri and junkiiyarri in (A.1). (All other morphology in (A.1) is glossed after Round (2013).)

$\begin{array}{lll}\text { (A.1) } & \text { Niya } & \text { wuunmarri, } \\ \text { ni-a } & \text { wui-c-n-wari } & \\ \text { 3SG-T } & \text { \{give-J }\}-\{\mu \mathrm{N}-\mu \mathrm{PRIV}\}-\mathrm{T} \\ \text { 3SG } & \text { give-NONVER } & \\ \text { dangkawalanymarri } & \text { junkiiyarri. } \\ \text { tajka+palat-wari+ki-a } & \text { cunki-ic-wari+ki-a } \\ \text { man- } \mu \text { PL- } \mu \text { PRIV- } \mu \text { LOC-T } & \{\text { straight- } \mu \text { SAME }\}-\mu \text { PRIV- } \mu \text { LOC-T } \\ \text { man-PL-PRIV-INS } & \text { in return }\} \text {-PRIV-INS } \\ \text { 'He never gives food back to other people.' [E228.ex.5-108] }\end{array}$

Two remarks can be made, which support the plausibility of this analysis. First, in (A.1) CASE:PRIVATIVE functions as a kind of negation predicate. Semantically, this is not identical to the usual function of the Kayardild PRIVATIVE CASE, which is to mark something which is lacking or absent, but it represents an entirely plausible, 
subsidiary function of a privative CASE category. Second, if the /-wari/ marker is taken to be a marker of CASE, then it is possible to argue cogently that the TAMA value in (A.1) is the same as that which we have seen previously in (28), namely TAMA:INSTANTIATED, even though in (A.1) there is no surface phonological marker of it: this is because the realization of TAMA:INSTANTIATED, if it were present, would come after the /-wari/ marker of CASE, and its underlying form would be /+ki/; the underlying string $/ \mathrm{i}+\mathrm{ki} /$ becomes [i] at the surface according to general phonological processes of Kayardild, and therefore is consistent with what we see in (A.1). Thus, there is nothing in what we already know about Kayardild inflection which militates against an analysis in which the /-wari/ in sentences like (A.1) is CASE:PRIVATIVE, and the TAMA value is INSTANTIATED.

Round (2013: 182-184) proposes a different analysis. Noting the similarity between the clausal distribution of the /-wari/ marker and clausal distributions of TAMA markers in general, Round proposes that /-wari/ marks a value of TAMA, dubbed NEGATORY. The athematic marker - $n$-marri is also analysed as a marker of TAM, namely TAMT:NONVERIDICAL. A glossing according to Round's analysis is in (A.2). However, our corpus survey raised three problems for Round's analysis.

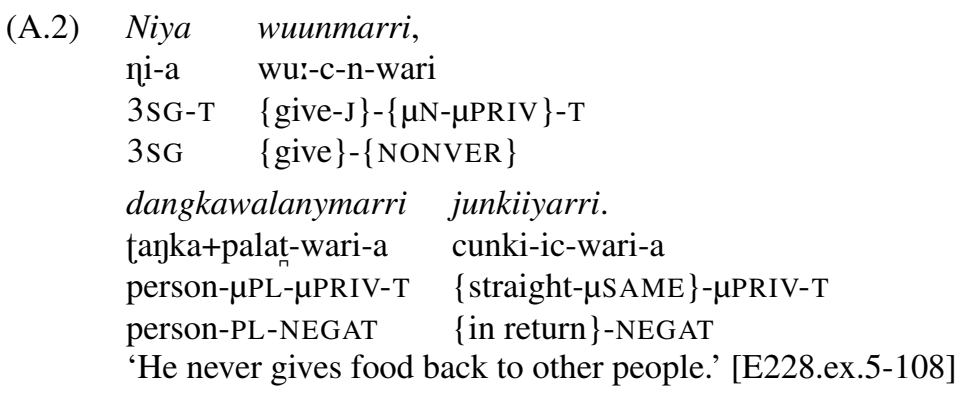

The problems for Round's analysis relate to the syntactic predictions entailed by the analysis of /-wari/ as a TAMA value. Exponents of TAMA ought to appear on words within DPs subordinate to one of the VP nodes $\mathrm{VP}_{\beta}, \mathrm{VP}_{\gamma}$ or $\mathrm{VP}_{\delta}$, shown in the syntactic structure (19) in Sect. 3.3. Moreover, if one DP in that VP is marked for the TAMA value, then all should be, because they would inherit their TAMA value in a precisely parallel fashion from the dominating VP node. Different predictions flow from an analysis of /-wari/ in terms of CASE. The privative CASE value would be free to appear on any $\mathrm{DP}$, not only those under $\mathrm{VP}_{\beta}, \mathrm{VP}_{\gamma}$ or $\mathrm{VP}_{\delta}$; and if it did appear on one DP within such a VP, there is no necessity that it should also appear on any others. Three pieces of evidence indicate that the analysis in terms of CASE is correct.

If /-wari/ is a marker of TAMA then it should appear on athematic stems in all DPs, without exception, under either $\mathrm{VP}_{\beta}, \mathrm{VP}_{\gamma}$ or $\mathrm{VP}_{\delta}$. To test this prediction, we require a sentence which contains more than one DP inside the relevant VP, of which at least one such DP is inflected with /-wari/; in such instances, all DPs should be marked with /-wari/. Such sentences are rare, but our corpus reveals two. Sentence (A.2) is consistent with the prediction from Round's analysis, however (A.3) is not: its DP2 carries the /-wari/ marker but its DP1 does not. Given all else that we know about Kayardild inflection, this indicates that the suffix /-wari/ in (A.3) cannot be realizing a value of TAMA. An analysis in terms of CASE:PRIVATIVE is feasible, however. 


\section{(A.3) [Binjarrinjiya $\left.{ }_{\mathrm{DP} 1}\right] \quad\left[\right.$ rawarriya $\left.{ }_{\mathrm{DP} 2}\right] \quad$ thulanmarri. pincarijci+ki-a ta-wari+ki-a tula-t-n-wari-a place name- $\mu$ LOC-T $\quad$ south- $\mu$ PRIV- $\mu$ LOC-T $\quad\{$ flow-J $\}-\{\mu N-\mu$ PRIV $\}-T$ place name-INS South-PRIV-INS \{flow $\}$-\{NONVER '[The creek] doesn't flow to the south at Binjarrinji.' [T1963]}

Implicit in Round's (2013) analysis of /-wari/ is that it conveys a simple negative predicate when, and only when, it realizes TAMA:NEGATORY, in contrast to the meaning 'absent, lacking' of the PRIVATIVE CASE. If that were so, a second prediction is that we should be able to identify all instances of simple negative /-wari/ with TAMA inflection. If so, then /-wari/ should never convey simple negation on subjects, since subject DPs never inflect for TAMA. However in (A.4), the verb of the second clause is marked with -n-marri, and we find the /-wari/ suffix on its subject DP, where its meaning is a simple negative predicate. Since this /-wari/ cannot be a marker of TAMA, we conclude that /-wari/ as a marker of PRIVATIVE CASE can convey a simple negative predicate.

\begin{tabular}{|c|c|c|c|}
\hline (A.4) & $\begin{array}{l}\text { Warirray } \\
\text { wałira+ki-a } \\
\text { nothing- } \mu \text { LOC-T } \\
\text { nothing-INS }\end{array}$ & $\begin{array}{l}\text { dulki } \\
\text { tulk+ki-a } \\
\text { place- } \mu \text { LOC-T } \\
\text { place-INS }\end{array}$ & $\begin{array}{l}\text { kurrij, } \\
\text { kuri-c-a } \\
\{\text { see-J }\}-\mathrm{T} \\
\{\text { see }\}\end{array}$ \\
\hline & $\begin{array}{l}\text { niwanmarri } \\
\text { ni+paj-wari-a } \\
\{3 \mathrm{SG}-\mu \mathrm{POSS}\}-\mathrm{PR} \\
\text { 3SG-PRIV }\end{array}$ & $\begin{array}{l}\text { warranm } \\
\text { wara-c-n- } \\
\{\text { go-J }\}-\{1 \\
\text { go-NONV }\end{array}$ & $\begin{array}{l}r i, \\
\text { ari-a } \\
\text { - } \mu \text { PRIV\}-T } \\
\text { R }\end{array}$ \\
\hline & $\begin{array}{l}\text { dathininja } \\
\text { tatin+inta- } \varnothing \\
\text { that- } \mu \text { OBL-T } \\
\text { that-SEJ }\end{array}$ & $\begin{array}{l}\text { rkathurrk. } \\
\text { ka-tr-kurka- } \varnothing \\
\text { ke-TH }\}-\{\mu \text { LOC. } \\
\text { ke\}-\{INS-SEJ }\}\end{array}$ & BL \}-T \\
\hline
\end{tabular}

'(They) can't see him anywhere, (no sign of) him going around, whom that one (Barrindindi) had just grabbed.' [E521.ex.12-75]

A third prediction of Round's analysis is that the NEGATORY TAMA value, realized by /-wari/, should only co-occur with the NONVERIDICAL TAMT value, realized by -n-marri. Yet we find two examples which contradict this prediction. In (A.5) and (A.6), DPs inflected with /-wari/ appear in clauses whose thematic stems are inflected not with - $n$-marri, but rather with the normal NEGATIVE POLARITY feature. The DP marked by /-wari/ in (A.5) is a subject, and in (A.6) is an object.
(A.5) maku+palat-wari-a
woman- $\mu$ PL- $\mu$ PRIV-T
Makuwalayarriya
burukuraajarriya;
woman-PL-PRIV
pufuku.ja:-c-wari-a
$\{$ make fire-J $\}-\mu$ PRIV-T
\{make fire $\}$-NEG.ACT

\section{bithiinbala burukuraaj. \\ piti:n+palat pu.qukuґa:-c-a \\ man- $\mu$ PL.T $\quad\{$ make fire-J $\}-T$ \\ man-PL \{make fire $\}$-ACT}

'Women don't make fire (with firesticks); men make fire.' [R2006-aug-10] 


$\begin{array}{llll}\text { (A.6) } & \text { Warraa, } & \text { kurrijarri } & \text { jawarri. } \\ \text { wara-a } & \text { kuri-c+wari-a } & \text { ca-wari+ki-a } \\ \text { far-T } & \{\text { see-J }\}+\mu \text { PRIV-T } & \text { track- } \mu \text { PRIV- } \mu \text { LOC-T } \\ \text { far-INS } & \{\text { see }\}-N E G . A C T & \text { track-PRIV-INS } \\ \text { '[They go] far, [till] they can't see their tracks.' [E1984] }\end{array}$

Taken together, our corpus examples indicate that Round's NEGATORY TAMA analysis of /-wari/ marking on DPs is untenable. For multiple reasons, the marker cannot be a realization of TAMA. In contrast, its distribution and semantics are consistent with PRIVATIVE CASE. We may add that when the verb of a clause is negated, either with - $n$-marri or by other means, then an available reading of CASE:PRIVATIVE is as a simple negative predicate. Accordingly, we remove NEGATORY from the list of TAMA values to be considered in Sects. 4-8.

A question then arises regarding the status of the -n-marri inflection on thematic stems, which Round (2013) analyses as TAMT:NONVERIDICAL. We turn to this next.

\section{A.3 NONVERIDICAL as a value of POLARITY, not TAM}

In this section our focus is on Round's (2013) TAMT:NONVERIDICAL feature, realized as -n-marri on thematic stems. We draw attention to an alternative, feasible analysis, according to which NONVERIDICAL is a value not of TAMT but of POLARITY.

In Round's (2013) system, there are two inflectional categories which share the properties of conveying clause-level semantic negation and appearing on thematic stems, though they are organized as values of two different morphosyntactic features: POlARITY:NEgATIVE and TAMT:NOnVERIDICAL. These are not the only similarities between them. In Appendix A.2 we saw that both license the reading of CASE:PRIVATIVE as a simple negation predicate. Recalling Sect. 4 and Sect. 5, we note that both combine semantically with other TAM features in a compositional manner, and that both are relatively free in terms of which athematic TAM values they combine with: NEGATIVE combines with seven TAMA values, and NONVERIDICAL with three. The chief difference is that POLARITY:NEGATIVE is typically realized morphologically as an affix distinct from TAMT, which follows it, whereas the NONVERIDICAL appears alone on the thematic stem, unaccompanied by any (other) overt marker of TAMT. Our essential observation here is that there is no substantial impediment to analysing the NONVERIDICAL as a value of POLARITY. A NONVERIDICAL value of POLARITY would simply be one which is not accompanied by an overt realization of TAMT. Recall from Sect. 3.5 that even POLARITY:NEGATIVE will at times be unaccompanied by a distinct realization of TAMT, so this is not overly surprising. ${ }^{40}$ The benefits of such a reorganization of the NONVERIDICAL would be that TAM and polarity in Kayardild would be partitioned into distinct morphosyntactic

\footnotetext{
${ }^{40}$ Another approach would be this: we argue that unlike the $\mu$ NEG marker /-nay/ which realizes POLARITY:NEGATIVE, the exponent of POLARITY:NONVERIDICAL is athematic; for this reason, we do no expect TAMT inflections to follow it (since TAMT only appears on thematic stems). Furthermore, one could argue, an overt realization of POLARITY blocks a realization of TAMA, and so even though the exponent of POLARITY:NONVERIDICAL is athematic, no realization of TAMA follows it. Blocking relationships like this are found elsewhere in the Kayardild inflectional system, for example between the two complementization features (Round 2013: 88-90).
} 
features; the semantic interaction with CASE:PRIVATIVE would uniformly be one between CASE:PRIVATIVE and POLARITY values; and the semantic compositionality and freedom of combination of TAM and POLARITY values would be principled, as opposed to being a curious accident as in Round's analysis, where the sole 'negative' TAMA feature happens also to be the most freely combinable in this manner. It is, of course, a frequent and expected situation to find negation cross-cutting with TAM. In Sects. 4-5, we discuss how organizing NONVERIDICAL in the POLARITY feature also allows us to better evaluate Kayardild's other TAMT features in relation to our question of whether we are dealing with one feature or two.

\section{A.4 The semantics of present tenses}

In this section we argue, contrary to Round's (2013) analysis, that Kayardild has only two distinct, present-like TAM types, not three. The issue here hinges upon (non)equivalences between TAM types in Kayardild's complementized clauses, which we abbreviate as c-clauses, and its uncomplementized full clauses, which we abbreviate as u-clauses. The key observational fact is that in c-clauses there is just one pattern of present-like TAM inflection, which we can call PRESENT-c, and in $\mathrm{u}$-clauses there are two, which we refer to here as PRESENT-u1 and PRESENT-u2. In terms of their TAM feature values, Round (2013) analyses all three as distinct, whereas Evans (1995a) treats PRESENT-c and PRESENT-u2 as equivalent, and thus distinguishes only two types. The feature values assigned to the PRESENT-u1, PRESENT-u2 and PRESENT-c by Round and Evans are summarized in Table A.1.

As we see in Table A.1, Evans' and Round's analyses are entirely parallel to one another with respect to the features TAMV/TAMT, which group together PRESENT-c and PRESENT-u2. The analyses differ with respect to MODAL CASE/TAMA, where Round (2013: 115) presents syntactic and semantic arguments for recognising a distinct TAMT:PRESENT feature value for PRESENT-c. Earlier, in Sect. 3.4, we discussed reasons why Round's syntactic arguments can be set aside, and consequently our argumentation in this section focuses on semantics. First, however, let us review the inflectional forms involved. In Table A.2 we list the morphomic exponents of these present-like TAM types, on thematic and athematic stems. Example sentences are in (A.7)-(A.9) below.

Table A.1 Feature values assigned to Kayardild's three present-like clause types

\begin{tabular}{llllll}
\hline & Evans (1995a) & & & Round (2013) & \\
\cline { 2 - 3 } \cline { 5 - 6 } & TAMV & MODAL CASE & & TAMT & TAMA \\
\hline PRESENT-u1 & ACTUAL & LOCATIVE & & ACTUAL & INSTANTIATED \\
PRESENT-c & IMMEDIATE & LOCATIVE & & IMMEDIATE & PRESENT \\
PRESENT-u2 & IMMEDIATE & LOCATIVE & IMMEDIATE & INSTANTIATED \\
\hline
\end{tabular}

Table A.2 Morphomic exponents of Kayardild's three present-like clause types

\begin{tabular}{lll}
\hline & On thematic stems & On athematic stems \\
\hline PRESENT-u1 & none & $\mu \mathrm{LOC}$ \\
PRESENT-c & $\mu \mathrm{LOC}$ & $\mu \mathrm{LOC}$ \\
PRESENT-u2 & $\mu \mathrm{LOC}$ & $\mu \mathrm{LOC}$ \\
\hline
\end{tabular}


Comparing Tables A.1 and A.2, we see that Evans' feature values exactly follow the pattern implied by the exponents. Round (2013) departs from this in the case of the athematic stems. Our argument here will be that Round was correct to depart from a strictly form-based assignment of feature values, but incorrect to set up a three-way featural contrast between PRESENT-u1, PRESENT-u2 and PRESENT-c. We can begin the argument with example sentences.

Sentence (A.7) illustrates PRESENT-u1, which has a default non-future meaning. The verb dalwanija has no overt marker of TAMV/TAMT, and consists morphologically of the verb stem followed by a termination (glossed T).

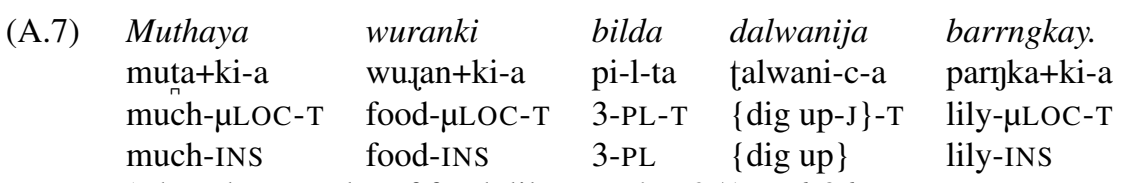

'They dug up a lot of food, lily roots.' [E251.ex.6-36]

Sentence (A.8) illustrates PRESENT-u2, which conveys an 'immediate' present, denoting fleeting events occurring right at the point of utterance (Evans 1995a: 256258).

\begin{tabular}{|c|c|c|}
\hline & $b i-l-d a$ & budii-j-iy-a \\
\hline 0 & 3-PL-T & $\{$ run away-J $\}-\mu \mathrm{LOC}-$ \\
\hline & $3-\mathrm{P}$ & $\{$ run away $\}$-IMM \\
\hline
\end{tabular}

kuujuu-j-i-ring-ki-.

$\{$ swim-J $\}-\{\mu$ LOC $-\mu$ ALL $\}-\mu L O C-T$

$\{$ swim $\}-\{$ DIRT $\}$-INS

'They're running away to the south to swim.' [R2005-jul-08]

Sentence (A.9) illustrates PRESENT-c, the sole present-like TAM type in c-clauses. In (A.9), PRESENT-c conveys a simultaneity between the event of the subordinate clause and that of the matrix clause.

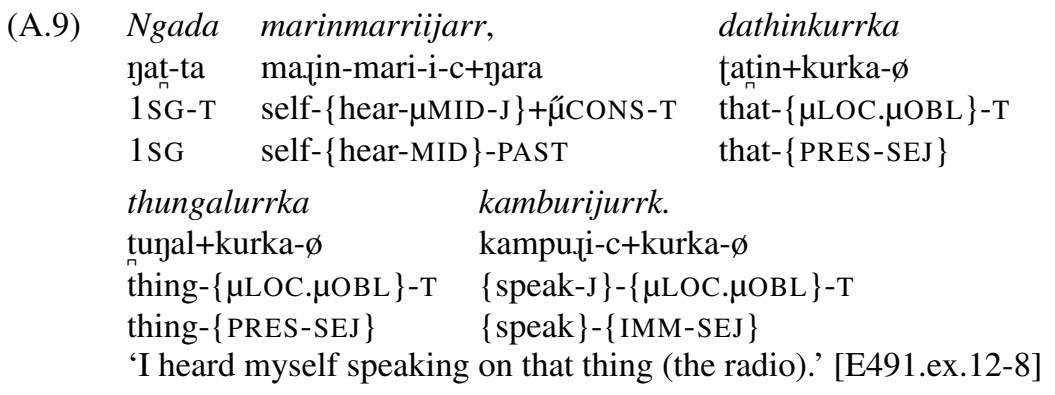

Evans (1995a: 511-512) and Round (2013: 115) both observe that PRESENT-c differs semantically from PRESENT-u1 and PRESENT-u2. Evans places this observation in the context of the tense semantics of subordinate c-clauses more generally. He notes that for all of Kayardild's TAM types which occur both in u-clauses and c-clauses, the semantics in subordinate c-clauses shifts, and in most cases is understood as relative to the matrix clause (Evans 1995a: 512). By this logic, it is appropriate to 
identify PRESENT-c with one of the two u-clause present-like tenses, PRESENT-u1 and PRESENT-u2. On this point, we agree with Evans. ${ }^{41}$ However, Evans matches PRESENT-c with PRESENT-u2, the 'immediate' present which shares the same exponents. In contrast, we draw attention to a second use of c-clauses, which is not as subordinate clauses but as topicalized main clauses, as in (A.10). In (A.10) we see that PRESENT-c, now in a main clause, has a general non-future meaning quite equivalent to PRESENT-u1.

\begin{tabular}{|c|c|c|c|c|}
\hline (A.10) & $\begin{array}{l}\text { Barrunthawurrka } \\
\text { parunta+kurka- } \varnothing \\
\text { yesterday- }\{\mu \mathrm{LOC} . \mu \mathrm{OBL}\}-\mathrm{T} \\
\text { yesterday- }\{\text { PRES-SEJ }\}\end{array}$ & $\begin{array}{l}\text { ngijuwa } \\
\text { nicu+pa- } \varnothing \\
1 \mathrm{SG}-\mu \mathrm{SEJ}-\mathrm{T} \\
1 \mathrm{SG}-\mathrm{SEJ}\end{array}$ & $\begin{array}{l}\text { kurrijurrka } \\
\text { kuri-c+kurka- } \varnothing \\
\{\text { see-J }\}-\{\mu \text { LOC. } \mu \text { OBL }\}-T \\
\{\text { see }\}-\{\text { IMM-SEJ }\}\end{array}$ & $\begin{array}{l}n i, \\
\text { ni-a } \\
3 \mathrm{SG}-\mathrm{T} \\
3 \mathrm{SG}\end{array}$ \\
\hline & $\begin{array}{ll}\text { yakuriya } & \text { burldija } \\
\text { jaku_i-a } & \text { pulti-c-a } \\
\text { fish-T } & \text { \{hit_with_project } \\
\text { fish } & \text { \{hit_with_project }\end{array}$ & $\begin{array}{rr} & \text { kam } \\
\text { tile-J }\}-\mathrm{Tam} \\
\text { tile }\} & \text { ston } \\
\text { ston }\end{array}$ & $\begin{array}{l}\text { arruru. } \\
\text { lar+kufu-a } \\
\text { e- } \mu \text { PROP-T } \\
\text { e-PROP }\end{array}$ & \\
\hline
\end{tabular}

Our conclusion from this is that Kayardild has a default non-future TAM type, which we identify with PRESENT-u1 and PRESENT-c, and label ACTUAL (following both Evans' and Round's practice when labelling it in u-clauses). In subordinate c-clauses, where all tense meanings are 'shifted', the ACTUAL TAM type is used as a simultaneous tense. In addition, Kayardild possesses an IMMEDIATE present (PRESENT-u2), which occurs only in u-clauses.

\section{A.5 Parsimony and the analysis of apprehensive clauses}

Many Australian languages possess an APPREHENSIVE category of TAM, which is used to refer to undesirable events which should be avoided (Dixon 1980: 380, Blake 1987: 136). Kayardild has three putative apprehensive TAM types. In this section we show that only two are well motivated, and of them, one appears to be restricted to complementized clauses. The third is rare and is ambiguous in the sense of Sect. 3.1.

Sentences (A.11)-(A.13) illustrate TAMT:APPREHENSIVE in combination with what appears at first to be TAMA:EMOTIVE, TAMA:FUTURE and TAMA:INSTANTIATED.

$\begin{array}{llll}\text { Dathina } & \text { wanku } & \text { baanyarra } & \text { ngijininj. } \\ \text { tatina } & \text { wanku-a } & \text { pa:-c-jara- } \varnothing & \text { jicu-ij-inta- } \varnothing \\ \text { that.T } & \text { shark-T } & \{\text { bite-J\}- } \mu \text { APPR-T } & \text { 1SG- } \mu \text { POSS- } \mu \text { OBL-T } \\ \text { that } & \text { shark } & \{\text { bite }\}-A P P R & \text { 1SG-POSS-EMO }\end{array}$

'That shark might bite me.' [E204.ex.5-20]

\footnotetext{
${ }^{41}$ Round (2013: 115) does not explicitly take this context into account, though his primary concern is with the syntactic issue, whose status we have reinterpreted (Sect. 3.4).
} 
(A.12) Dankiya rikaya dulki, jungarray, malantha

$\begin{array}{lllll}\text { tan+ki-a } & \text { fika+ki-a } & \text { tulk+ki-a } & \text { cunara+ki-a } & \text { mala-inta- } \varnothing \\ \text { this- } \mu \text { LOC-T } & \text { cold- } \mu \text { LOC-T } & \text { place- } \mu \text { LOC-T } & \text { big- } \mu \text { LOC-T } & \text { sea- } \mu \text { OBL-T } \\ \text { this-LOC } & \text { cold-LOC } & \text { place-LOC } & \text { big-LOC } & \text { sea-SEJ }\end{array}$

wanjiinyarrantha

ngakuluwanjuunth!

wajci:-c+para-inta- $\varnothing \quad$ ya-ku-lu+paj+kuu-inta- $\varnothing$

\{ascend-J $\}-\mu$ APPR- $\mu O B L-T \quad 1-2-P L-\mu P O S S-\mu$ PROP- $\mu O B L-T$

\{ascend $\}$-APPR-SEJ 1-2-PL- $\varnothing$-FUT-SEJ

'(Even) in this cold place up high the sea might climb up to us.' [W1960;

R112.ex.5-43]

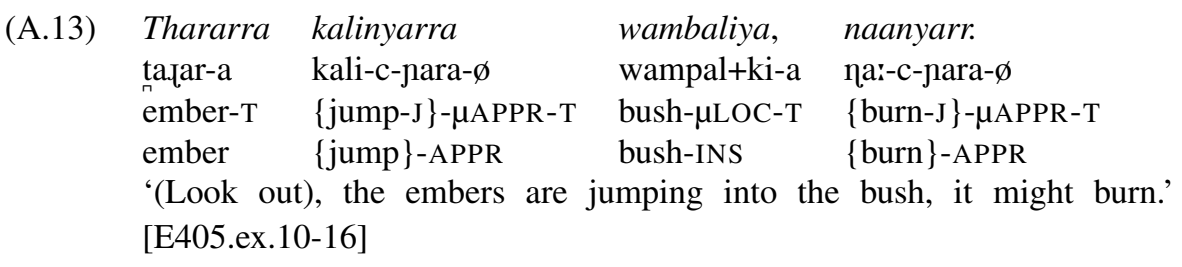

Apprehensive clauses such as (A.13), with TAMA:EMOTIVE, represent the norm and occur many dozens of times in our corpus. The other two require comment.

Apprehensive clauses with TAMA:FUTURE are restricted. In complementized apprehensives, TAMA:FUTURE is used as frequently as TAMA:EMOTIVE. Our corpus contains six instances of the former and five of the latter, ${ }^{42}$ and from this small set of sentences, we were able to identify no obvious semantic difference between them. ${ }^{43}$ The relative frequencies of TAMA:FUTURE and TAMA:EMOTIVE in uncomplementized clauses are starkly different. In uncomplementized clauses, our corpus contains many dozen instances of TAMA:EMOTIVE but only two putative examples of TAMA:FUTURE, one of which we will discount. ${ }^{44}$ The other is (A.14), cited by Evans (1995a: 3,405). ${ }^{45}$

\footnotetext{
${ }^{42}$ Evans (1995a: 132) states that in complementized clauses the usual TAMT:EMOTIVE (his OBLIQUE MODAL CASE) 'is replaced by' TAMT:FUTURE (his PROPRIETIVE MODAL CASE) but our evidence does not support this.

${ }^{43}$ Evans (1995a: 405) suggests that by using TAMA:FUTURE 'the speaker stresses his certainty of being able to effect an unpleasant retaliation', but the same connotation is absent in clauses like (A.12).

${ }^{44}$ The discounted example is (a), which is cited by Evans (1995a: 132) along with a corresponding TAMA:EMOTIVE version and a complementized version (Evans 1995a: 132); it contains an unexpected form balanyarra (expected balanharra), and we suspect it may be linguists' construction, or uttered by a speaker of non-classical Kayardild.
}

\begin{tabular}{|c|c|c|}
\hline $\begin{array}{l}N g a d a \\
\text { yat-ta }\end{array}$ & $\begin{array}{l}\text { balanyarra }(\mathrm{sic}) \\
\text { pala-t-jara- } \emptyset\end{array}$ & $\begin{array}{l}\text { nguтьапји. } \\
\text { juү+рај1+kuu-ø }\end{array}$ \\
\hline $1 \mathrm{SG}-\mathrm{T}$ & $\{$ hit-J $\}-\mu$ APPR-T & 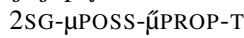 \\
\hline $1 \mathrm{SG}$ & $\{$ hit $\}-A P P R$ & 2SG-Ø-FUT \\
\hline
\end{tabular}

\footnotetext{
${ }^{45}$ Example (A.14) is also minimally different from a complementized version recorded by Wurm, thus it may be a linguist's construction, or uttered by a speaker of non-classical Kayardild.
} 


\section{(A.14) Nyingka ngudina wangalk, \\ jị+ka juti-c-nay- $\varnothing \quad$ wayalk+ka \\ 2SG-T $\quad$ throw-J $\}-\mu N E G-T$ boomerang-T \\ 2SG \{throw $\}$-NEG.IMP boomerang \\ ngada ngumbanju burldinyarr. \\ yat-ta yuj+pan+kuu- $\varnothing \quad$ pu.ti-c-nara- $\varnothing$ \\ 1SG-T 2SG- $\mu$ POSS- $\mu$ PROP-T $\quad\{$ throw-J $\}-\mu$ APPR-T \\ $1 \mathrm{SG} \quad 2 \mathrm{SG}-\varnothing$-FUT $\quad\{$ throw $\}$-APPR \\ 'Don't you throw the boomerang, or I'll throw one at you.' [E205.ex.10-15]}

Example (A.14) is ambiguous. In (A.14) the putative TAMT:FUTURE inflection is marked by $\mu$ PROP, however Kayardild also uses $\mu$ PROP to inflect intended objects of actions for CASE:PROPRIETIVE (Evans 1995a: 148). We suggest that in (A.14) the 'intentional object' analysis is correct. According to that analysis, the TAMA value of the second clause in (A.14) is EMOTIVE, and therefore the same as all other attested uncomplementized apprehensives. In (A.14) TAMA:EMOTIVE is not overtly marked, but its overt absence is as predicted, since intentional objects sit higher in the syntactic tree (A.14) than $\mathrm{VP}_{\gamma}$, to which TAMA:EMOTIVE attaches (Round 2013: 116, 272-273).

Next we consider apprehensives with putative TAMA:INSTANTIATED, which is realized by $\mu$ LOC. Sentence (A.13) above, with putative TAMA:INSTANTIATED, is cited at two places in Evans (1995a: 3, 405). Example (A.15) is a sentence with identical form recorded by Wurm, except for an extra suffix on the final word. A discussion of (A.15) will allow us to raise a number of issues relevant to the more complex case of (A.13), so we begin with it.

$\begin{array}{llll}\text { (A.15) } & \text { Thararra } & \text { kalinyarra } & \text { wambaliya } \\ \text { tajar-a } & \text { kali-c-jara- } \varnothing & \text { wampal+ki-a } \\ \text { ember-T } & \text { \{jump-J\}- } \mu \text { APPR-T } & \text { bushfire- } \mu \text { LOC-T } \\ \text { ember } & \text { \{jump\}-APPR } & \text { bushfire }^{46}-\mathrm{COMP}\end{array}$

naanyarranth.

na:-c-jara-inta- $\varnothing$

\{burn-J $\}-\mu$ APPR- $\mu$ OBL-T

\{burn $\}$-APPR-SEJ

'The embers are jumping (out of the fire); we may get a bushfire here.' [W1960]

The final word of (A.15) is inflected for SEJUNCT complementization (glossed SEJ), one of Kayardild's two complementization features. ${ }^{47}$ This tells us that (A.15) contains two clauses, the first uncomplementized and the second complementized. The most straightforward account of the word wambaliya in (A.15) is as a focalized subject DP which sits inside the second, complementized clause. Focus DPs inflect for the second of Kayardild's complementization features, plain COMPLE-

\footnotetext{
${ }^{46}$ The root wambal- is polysemous. In (A.15) the speaker used it as a translation of the English 'bushfire'. In (A.13) it appears to mean 'bush'.

${ }^{47}$ Regarding these features, see our earlier footnote, 27.
} 
MENTIZATION (glossed COMP). Focus DPs in Kayardild can occur within complementized clauses or can be freestanding. They are reported in Evans (1995a: 141142) only in relation to freestanding instances, but are discussed at some length in Round (2013: 95-96). For current purposes, it should be noted that the COMP feature which marks words in focus DPs is realized by the same $\mu$ LOC suffix that realizes TAMA:INSTANTIATED. In addition, focus DPs escape all inflection for TAM, due to their high syntactic position, cf. (19). Consequently, in sentence (A.15) both clauses can be analysed as regular apprehensives. Their TAMA value is not INSTANTIATED but EMOTIVE. The regular, TAMA:EMOTIVE value receives no overt realization, because neither clause in (A.15) contains a DP below $\mathrm{VP}_{\gamma}$, the $\mathrm{VP}$ node to which TAMA:EMOTIVE attaches.

Let us now return gradually to Evans' example, (A.13). Sentence (A.13) does not contain a complementized clause, so its analysis will be different to (A.15). Our corpus contains just three other clauses whose structure is parallel to (A.13), that is, clauses that are uncomplementized apprehensives, accompanied by a DP marked with $\mu$ LOC. We may begin with example (A.16), which is revealing.

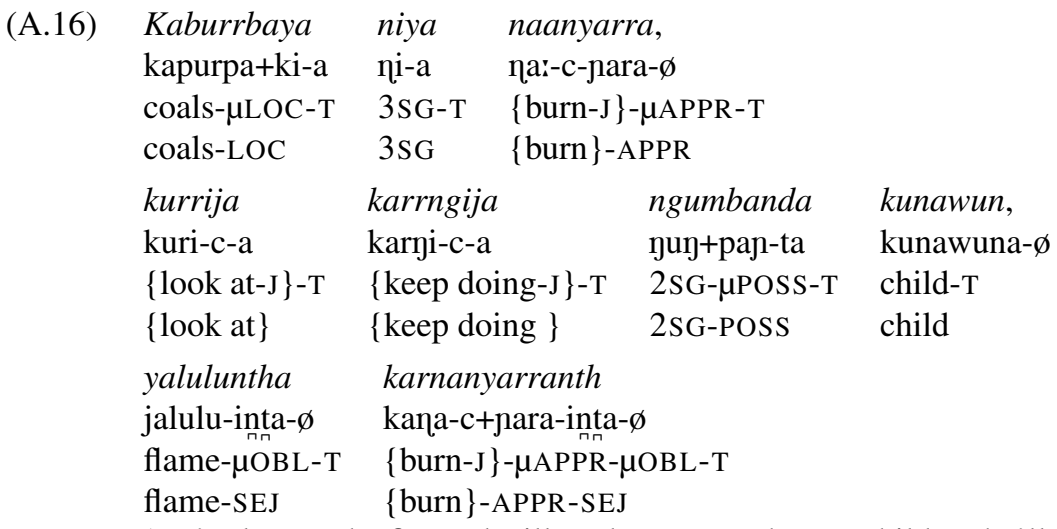

'He's close to the fire and will get burnt. Watch your child, or he'll get burnt in the flames.' [W1960]

Of the three clauses in (A.16), both the first and last are apprehensives. The final clause is a regular apprehensive. Its TAMA:EMOTIVE value is realized on the location denoting DP yaluluntha 'in the flames'. This is normal in Kayardild, where location denoting DPs typically inflect for TAMA (Round 2013: 116, 146-150). In the first clause though, the location denoting DP kaburrbaya is inflected with $\mu \mathrm{LOC}$, which we might at first suppose is a realization of TAMA:INSTANTIATED. However, Evans' (1995a: 3) claim was that apprehensives with TAMA:INSTANTIATED should denote undesirable events already taking place. This is not true in the first clause of (A.16); the event of the child's burning lies, hopefully to be averted, in the future. Thus, either we must weaken our claim about the semantics of TAMA:INSTANTIATED apprehensives, or seek another analysis. Two other analyses are possible.

The first alternative analysis of (A.16) is that in kaburrbaya the $\mu \mathrm{LOC}$ is a marker of LOCATIVE CASE and that kaburrbaya modifies the subject. Two semantic interpretations would be available for the sentence: either as 'he, at the fire, might burn', or 'he, in the fire, might burn'. On the first reading, the LOCATIVE DP refers to the 
subject's current location, and in terms of scope, the 'undesirability' conveyed by the clause pertains solely to the clausal predicate 'burn'. On the second reading, 'undesirability' scopes over the whole clause, including the to-be-averted location of the subject 'in the fire'. As we will see soon, the second interpretation is always available in these examples; the first is not. Returning to the mechanics of inflection, because it modifies the subject, the DP kaburrbaya would not inflect for TAMA, cf. (19), and correspondingly, one could safely assume that (A.16) is a regular apprehensive clause with TAMA:EMOTIVE. We do not see any realization of EMOTIVE because there are no DPs in the right position to inflect for it.

A second alternative analysis of (A.16) is that in kaburrbaya the $\mu \mathrm{LOC}$ is a marker of COMP, and the DP kaburrbaya is a freestanding focus DP, syntactically outside of the rest of the clause. Freestanding focus DPs are often used in Kayardild to draw attention to the existence of the DP's referent (Round 2013: 95). In this case, one would assume the addressee is already aware of the existence of the fire, so the focus DP analysis is perhaps doubtful.

In sum, there are three potential analyses of (A.16). First, kaburrbaya is inflected for TAMA:INSTANTIATED; if this is so then we need to revise the putative semantics of TAMA:INSTANTIATED apprehensives, so that they do not refer solely to events that are already occurring. Second, kaburrbaya is LOCATIVE modifier of the subject, denoting either 'at the fire' (outside the scope of 'undesirable') or 'in the fire' (under the scope be 'undesirable'). Third, kaburrbaya is a focus DP, though this is perhaps doubtful. Let us turn next to (A.17) and (A.18).

\begin{tabular}{|c|c|c|c|c|c|}
\hline (A.17) & $\begin{array}{l}\text { Dathinki } \\
\text { tatin+ki-a } \\
\text { that- } \mu \text { LOC-T } \\
\text { that-INS }\end{array}$ & $\begin{array}{l}\text { ngambuya } \\
\text { yampu+ki-a } \\
\text { hole- } \mu \text { LOC-T } \\
\text { hole-INS }\end{array}$ & $\begin{array}{l}\text { barjinyarra } \\
\text { pałci-c-jara- } \varnothing \\
\{\text { fall-J }\}-\mu \text { APPR-T } \\
\{\text { fall }\}-A P P R\end{array}$ & $\begin{array}{l}\text { kunyaa } \\
\text { kuja-a } \\
\text { small-T } \\
\text { small }\end{array}$ & $\begin{array}{l}\text { kunawun } \\
\text { kunawuna- } \varnothing \\
\text { child -T } \\
\text { child } \\
\text { W1960l }\end{array}$ \\
\hline
\end{tabular}

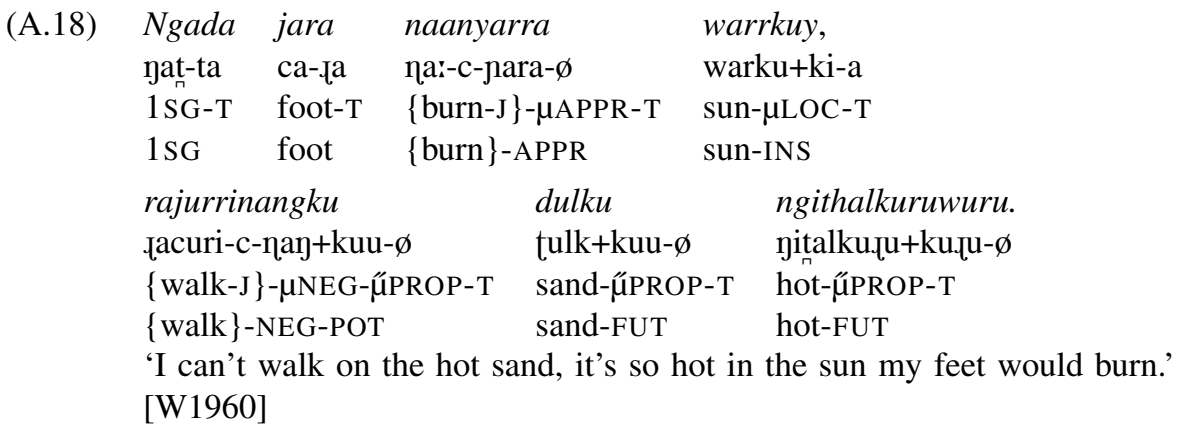

Just like (A.16), sentences (A.17) and (A.18) are three-way ambiguous. The DPs marked with $\mu$ LOC denote locations or environmental conditions, and so can be interpreted in various ways. The first is that $\mu$ LOC realizes TAMA:INSTANTIATED, provided, as before, that we relax the semantic conditions on TAMA:INSTANTIATED apprehensives. It could also be realizing CASE:LOCATIVE, in which case it modifies the subject, though interestingly in these instances, this only works if we interpret the 
DP in question as falling under the scope of 'undesirable': 'in the hole', 'in the sun'. And $\mu \mathrm{LOC}$ could be a realization of COMP, marking a freestanding focus DP. This seems plausible in (A.17) where the speaker is calling attention to the existence of the hole, but perhaps less so in (A.18), where calling attention to the sun seems less likely. Let us now examine the final example in our corpus, namely our example from Evans (1995a), repeated here in (A.19).

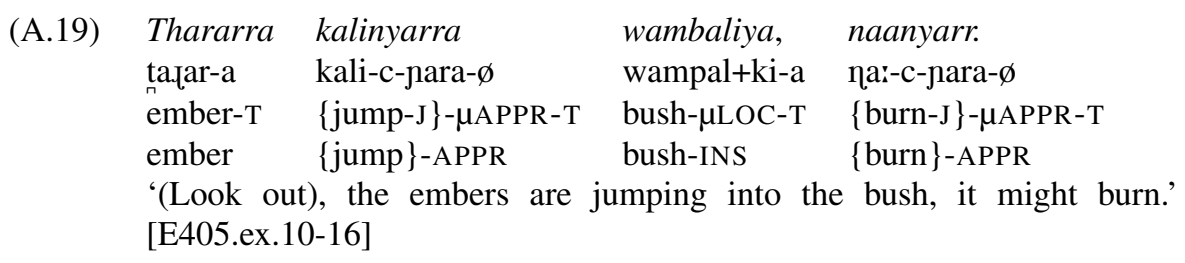

In (A.19), the DP marked with $\mu$ LOC once again denotes a location, and so is threeway ambiguous for the same reasons as above (in this case the location is a destination, though that is no cause for concern; in Kayardild destinations are most often inflected the same as static locations).

In sum, there are just four known clauses which are similar to (A.19), including (A.19) itself. If we wish to argue that $\mu$ LOC in those clauses realizes TAMA:INSTANTIATED, then we will need to relax the semantic definition of TAMA:INSTANTIATED apprehensives. Moreover, all four of the DPs which putatively inflect for TAMA:INSTANTIATED are DPs that denote locations (or DPs which Kayardild grammar treats as locations); conversely, none of the attested apprehensive clauses in Kayardild which contain direct objects use TAMA:INSTANTIATED. There is a simple and parsimonious account of this. Namely, Kayardild does not possess TAMA:INSTANTIATED apprehensive clauses. The DPs in our four examples above, which are marked by $\mu \mathrm{LOC}$, are DPs in the LOCATIVE CASE. The one proviso, is that the 'undesirable' meaning in apprehensive clauses must be understood as (at least potentially) taking scope over the entire clause, including the subject DP and its modifiers.

To summarize Appendix A.5, we began with three putative apprehensive TAM types in Kayardild. The first, with TAMA:EMOTIVE is widely attested. The second, with TAMA:FUTURE is restricted to complementized clauses. Judging from a small set of examples, its semantics are not distinct from clauses which use TAMA:EMOTIVE. The third type, with putative TAMA:INSTANTIATED is attested in four tokens. In all of these, the $\mu$ LOC suffix which would mark TAMA:INSTANTIATED is also consistent with two alternative analyses, of which the most convincing is that $\mu$ LOC marks CASE:LOCATIVE. We conclude that the simplest and most unproblematic analysis of the data is that Kayardild has just two apprehensive TAM types, one with TAMA:EMOTIVE and one, restricted to complementized clauses, with TAMA:FUTURE.

\section{A.6 The counterfactual use of non-future potentials}

In this section we draw attention to the fact that the combination of TAMA:INSTANTIATED and TAMT:POTENTIAL is used only in counterfactual clauses. This is relevant for our analysis in Sect. 5 of the semantic compositionality of TAM. 
Between examples (A.20) and (A.21) ${ }^{48}$ the TAM contrast appears to be one of tense; the former is a future (negative) potential and the latter a non-future (negative) potential. The TAM features involved, following Round (2013), are \{ TAMA:FUTURE \& TAMT:POTENTIAL\} in (A.20) and \{TAMA:INSTANTIATED \& TAMT:POTENTIAL\} in (A.21); and both sentences are negated.

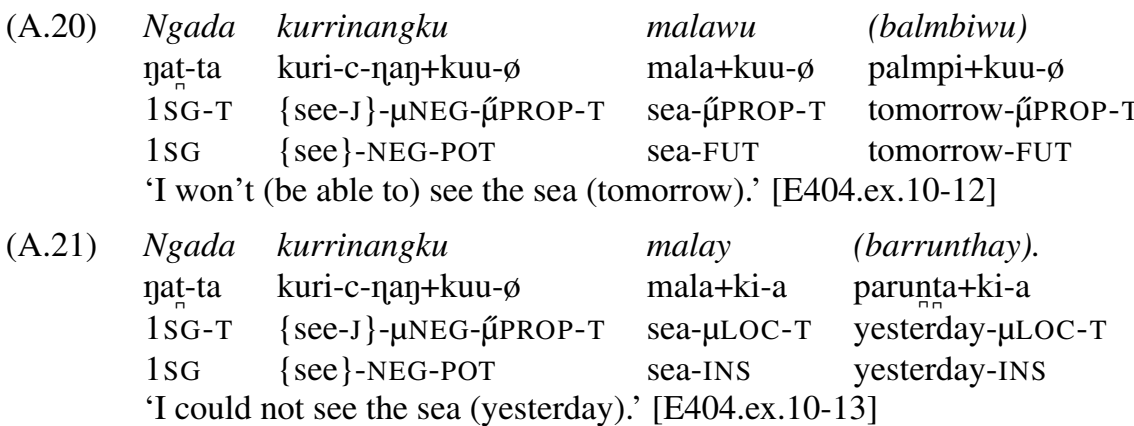

The full story, however, is more subtle. Firstly, if we search for positive polarity counterparts to (A.20) we find them in abundance, but positive counterparts to (A.21) are not attested. Instead, positive polarity non-future potentials in Wurm's corpus are translated into Kayardild with the TAM categories not of (A.21), but of (A.20), as seen in the second clause of (A.22).

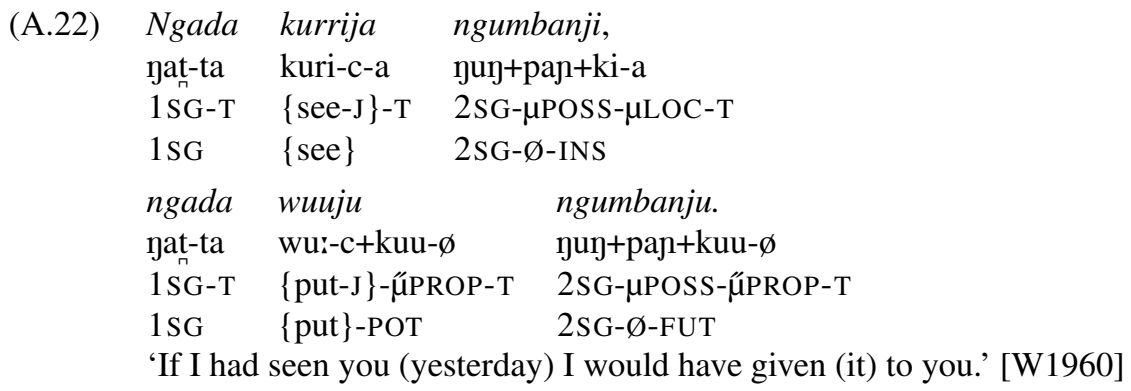

As for clauses with TAMA:INSTANTIATED \& TAMT:POTENTIAL, the total number in our corpus is just five, and all appear in counterfactual contexts. In (A.21) above, counterfactuality is entailed by the presence of the negation feature, and in (A.23)(A.24) by Kayardild's counterfactual particles maraka and mara.

\begin{tabular}{|c|c|c|c|}
\hline (A.23) & $\begin{array}{l}\text { Maraka } \\
\text { majaka- } \emptyset\end{array}$ & $\begin{array}{l}\text { ngudiju } \\
\text { juti-c+kuu- }\end{array}$ & $\begin{array}{l}\text { bangay. } \\
\text { paya+ki-a }\end{array}$ \\
\hline & CNTRFCT & $\{$ throw-J $\}-\mu$ PROP-T & turtle- $\mu \mathrm{LOC}-\mathrm{T}$ \\
\hline & CNTRFCT & $\{$ throw $\}$-POT & turtle-INS \\
\hline
\end{tabular}

'(They) could have thrown the turtle (overboard, to lighten the boat), but didn't.' [E259.ex.9-252]

\footnotetext{
${ }^{48}$ These repeat our earlier examples (6) and (7), but with glossing following Round (2013).
} 


\section{(A.24) Mara ngada barndiju barrunthay. \\ maja- $\varnothing$ jat-ta panti-c+kuu- $\varnothing \quad$ parunta+ki-a \\ CNTRFCT $1 \mathrm{SG}-\mathrm{T} \quad$ \{block-J $\}-\mu$ PROP-T yesterday- $\mu$ LOC-T \\ CNTRFCT $1 \mathrm{SG} \quad$ \{block\}-POT yesterday-INS \\ 'I could have prevented him from going yesterday (but didn't).' [E1984]}

In sum, it appears at first glance from (A.20) and (A.21) that \{ TAMA:INSTANTIATED \& TAMT:POTENTIAL $\}$ simply marks the non-future potential, however it is conspicuous that all attested uses of this TAM type are counterfactuals. Moreover, the absence of any non-counterfactual clauses marked by \{TAMA:INSTANTIATED \& TAMT:POTENTIAL $\}$, and the use of other TAM categories to mark the noncounterfactual non-future potentials in our corpus, suggest that the usage of \{ TAMA: INSTANTIATED \& TAMT:POTENTIAL $\}$ was infelicitous in anything but counterfactual clauses. Faced with such evidence, a reasonable conclusion is that \{TAMA:INSTANTIATED \& TAMT:POTENTIAL\} was a dedicated counterfactual TAM type in Kayardild, with the proviso that it seems to have appeared only in clauses where other elements also contributed a counterfactual meaning.

\section{A.7 Summary}

In Appendix A.1 we introduced our corpus and outlined our reasons for exercising care with respect to the representativeness of examples which lack a known, associated audio recording. In Appendix A.2 we gave syntactic arguments for the removal of Round's (2013) TAMA:NEGATORY value from the inventory of athematic TAM values, and in Appendix A.3 observed that Round's NONVERIDICAL value could viably be moved from the TAMT feature to POLARITY. In Appendix A.4 we simplified Kayardild's present tense TAM system and removed Round's (2013) TAMA:PRESENT. In Appendix A.5 we simplified Kayardild's range of apprehensive clauses, noting the apparent semantic equivalence of apprehensives that USe TAMA:FUTURE and TAMA:EMOTIVE; and reanalysing all putative tokens of TAMA:INSTANTIATED clauses. In Appendix A.6 we found that the combination of TAMA:INSTANTIATED and TAMT:POTENTIAL has a consistently counterfactual usage. At the end of this process, a revised list of eleven TAMT and fifteen TAMT values is given in (A.25)-(A.26).

(A.25) Values of TAMT (revised list)

ACTUAL, ANTECEDENT, APPREHENSIVE, DIRECTED, DESIDERATIVE, HORTATIVE, IMMEDIATE, IMPERATIVE, INCIPIENT, NONVERIDICAL, PAST, POTENTIAL, PRECONDITION, PROGRESSIVE, RESULTATIVE

(A.26) Values of TAMA (revised list)

ANTECEDENT, CONTINUOUS, DIRECTED, EMOTIVE, FUNCTIONAL, FUTURE, INCIPIENT, INSTANTIATED, PRECONDITION, PRIOR, ZERO ${ }^{49}$

\footnotetext{
${ }^{49}$ The final value here, which has no overt phonological realization, is labelled zero. In Round's constraintbased analysis of Kayardild's realizational morphology, it is important to make the difference between 'ZERO' TAMA (which blocks the overt realization of TAMT on the same word) and no TAMA at all, which would not do so (Round 2013: 234, fn. 6). One advantage of adopting a one-feature analysis is that the
} 
These are the values we consider in Sects. 4-8. That discussion leads us in turn to the conclusion that Kayardild can best be analysed with a single feature for TAM.

\section{References}

Arkad'ev, Petr. M. [Arkadiev, Peter M.] (in press). Teorija grammatiki v svete faktov jazyka kajardilt [The theory of grammar in the light of data from Kayardild]. Voprosy jazykoznanija.

Aronoff, M. (1994). Morphology by itself: Stems and inflectional classes. Linguistic inquiry monograph: Vol. 22. Cambridge: MIT Press.

Baerman, M., \& Corbett, G. G. (2013). Person by other means. In D. Bakker \& M. Haspelmath (Eds.), Languages across boundaries: Studies in memory of Anna Siewierska (pp. 1-14). Berlin: De Gruyter.

Baerman, M., Brown, D., \& Corbett, G. G. (2005). The syntax-morphology interface: A study of syncretism. Cambridge: Cambridge University Press.

Bakker, P. (1997). A language of our own: The genesis of Michif, the mixed Cree-French language of the Canadian métis. Oxford: Oxford University Press.

Bakker, P., \& Papen, R. A. (1997). Michif: A mixed language based on Cree and French. In S. G. Thomason (Ed.), Creole language library: Vol. 17. Contact languages: A wider perspective (pp. 295-363). Amsterdam: John Benjamins.

Bank, S. (2014). The algebraic structure of morphosyntactic features. Nordlyd, 41, 239-259.

Belyaev, O. I. (2014). Osetinskij kak jazyk s dvuxpadežnoj sistemoj: gruppovaja fleksija i drugie paradoksy padežnogo markirovanija [Ossetic as a language with a double case system: Phrasal inflection and other paradoxes of case marking]. Voprosy jazykoznanija, 6, 31-65.

Blake, B. J. (1987). Australian aboriginal grammar. London: Croom Helm.

Chomsky, N. (2001). Derivation by phase. In M. Kenstowicz (Ed.), Ken Hale: A life in language (pp. 1-52). Cambridge: MIT Press.

Corbett, G. G. (2000). Number. Cambridge: Cambridge University Press.

Corbett, G. G. (2006). Agreement. Cambridge: Cambridge University Press.

Corbett, G. G. (2010). Classic problems at the syntax-morphology interface: Whose are they? In S. Müller (Ed.), Proceedings of the HPSG 2010 conference (pp. 255-268). Paris: Université Paris Diderot, Paris 7. CSLI Publications. http://cslipublications.stanford.edu/HPSG/2010/toc.shtml.

Corbett, G. G. (2012). Features. Cambridge: Cambridge University Press.

Corbett, G. G., \& Fedden, S. (2015). Features, orthogonality, typology. Paper read at the Società di Linguistica Italiana, University of Malta, 26 September 2015.

Dench, A., \& Evans, N. (1988). Multiple case-marking in Australian languages. Australian Journal of Linguistics, 8, 1-47.

Dixon, R. M. W. (1980). The languages of Australia. Cambridge: Cambridge University Press.

Evans, N. D. (1982-1998). Kayardild field recordings. Audio recordings held at the library of the Australian Institute of Aboriginal and Torres Strait Islander Studies [item EVANS_N03].

Evans, N. D. (1995a). A grammar of Kayardild: With historical-comparative notes on Tangkic. Berlin: Mouton de Gruyter.

Evans, N. D. (1995b). Multiple case in Kayardild: Anti-iconic suffix order and the diachronic filter. In F. Plank (Ed.), Double case: Agreement by suffixaufnahme (pp. 396-428). New York: Oxford University Press.

Evans, N. D. (1995c). Kayardild language tutorial. In: Linguistics association of Great Britain, autumn meeting, 18-20 September, 1995. Colchester: University of Essex.

Evans, N. (2003). Typologies of agreement: Some problems from Kayardild. In D. Brown, G. G. Corbett, \& C. Tiberius (Eds.), Agreement: A typological perspective (Special issue of Transactions of the Philological Society, Vol. 101, No. 2) (pp. 203-234). Oxford: Blackwell.

Evans, N. (2015). Inflection in Nen. In M. Baerman (Ed.), The Oxford handbook of inflection (pp. 543575). Oxford: Oxford University Press.

entire apparatus of TAM blocking becomes unnecessary. Rather than requiring TAMA and TAMV to block one another in different ways on different stems, it would suffice to state that a single TAM feature in the general case receives exponence on both stem types (thematic and athematic), and that for some values of the feature one or other stem type carries no overt exponent. 
Frajzyngier, Z. (2004). Tense and aspect as coding means for information structure: A potential areal feature. Journal of West African Languages, 30(2), 53-67.

Goddard, C. (1982). Case systems and case marking in Australian languages: A new interpretation. Australian Journal of Linguistics, 2, 167-196.

Haviland, J. (1979). Guugu Yimidhirr. In R. M. W. Dixon \& B. J. Blake (Eds.), Handbook of Australian languages (pp. 27-180). Canberra: Australian National University Press.

van Helden, W. A. (1993). Case and gender: Concept formation between morphology and syntax (II volumes). Studies in Slavic and general linguistics: Vol. 20. Amsterdam: Rodopi.

Nordlinger, R. (1998). Constructive case. Stanford: CSLI.

Nordlinger, R., \& Sadler, L. (2004a). Nominal tense in crosslinguistic perspective. Language, 80(4), 776806.

Nordlinger, R., \& Sadler, L. (2004b). Tense beyond the verb: Encoding clausal tense/aspect/mood on nominal dependents. Natural Language and Linguistic Theory, 22, 597-641.

Round, E. R. (2005). A first Kayardild audiovisual text corpus, with prosodic annotations: End of award report (FTG0025). New Haven: Yale University.

Round, E. R. (2007). Linguistic and ethnographic documentation of Kayardild: End of award report (IGS0039). New Haven: Yale University.

Round, E. R. (2009). Kayardild morphology, phonology and morphosyntax. PhD dissertation, Yale.

Round, E. R. (2011). Morphomes as a level of representation capture unity of exponence across the inflection-derivation divide. Linguistica, 51, 217-230.

Round, E. R. (2013). Kayardild morphology and syntax. Oxford: Oxford University Press.

Round, E. R. (2015). Rhizomorphomes, meromorphomes and metamorphomes. In M. Baerman, D. Brown, \& G. G. Corbett (Eds.), Understanding and measuring morphological complexity (pp. 29-52). Oxford: Oxford University Press.

Round, E. R. (2016). Kayardild inflectional morphotactics is morphomic. In A. Luís \& R. BermúdezOtero (Eds.), The morphome debate: Diagnosing and analysing morphomic patterns (pp. 228-247). Oxford: Oxford University Press.

Tindale, N. B. (1963). Recordings, Gulf of Carpentaria expedition 1963. Held by South Australian museum [item AA338/11/22].

Wittenburg, P., Brugman, H., Russel, A., Klassmann, A., \& Sloetjes, H. (2006). ELAN: A professional framework for multimodality research. In Proceedings of LREC 2006, fifth international conference on language resources and evaluation (pp. 1556-1559). http://tla.mpi.nl/tools/tla-tools/elan/.

Wurm, S. A. (1960). Recordings made in the Gayadilt language of Bentinck Island. Audio recordings held at the library of the Australian Institute of Aboriginal and Torres Strait Islander studies [items WURM_S01;2173-2174].

Zwicky, A. M. (1986). German adjective agreement in GPSG. Linguistics, 24, 957-990. 